\title{
MEMORLAS DE LEITURA DE EDUCADORAS E EDUCADORES DO CAMPO
}

\author{
Wils Prits RaEFIR

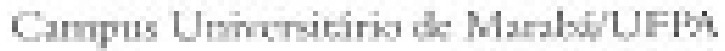 \\ nitakuphin

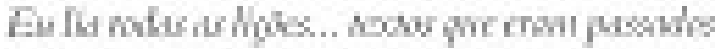

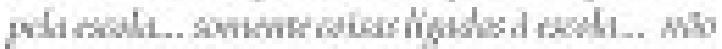

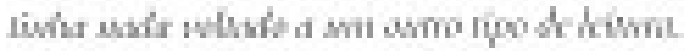

Fifurafore do cumpi

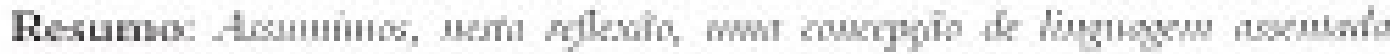

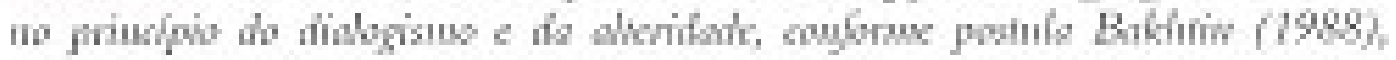

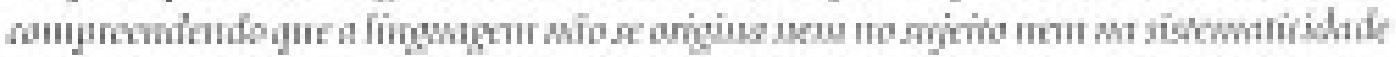

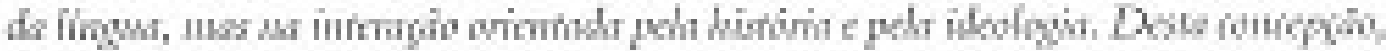

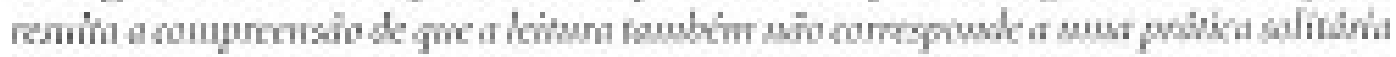

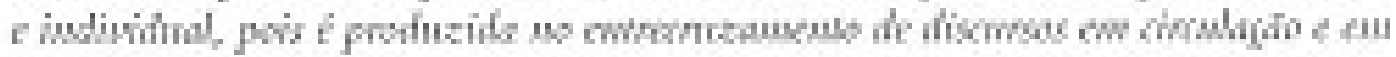

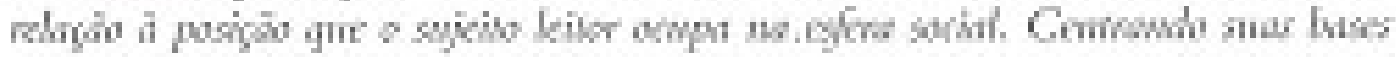

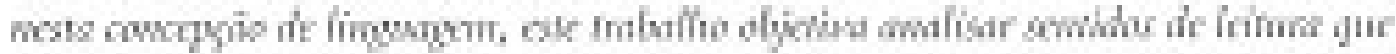

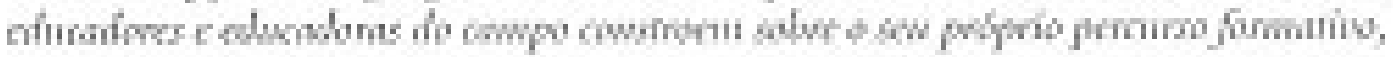

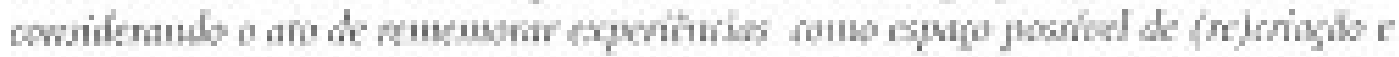
ownys if thow alwes

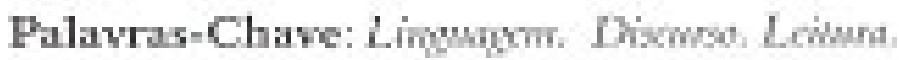

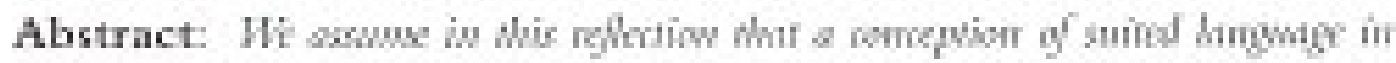

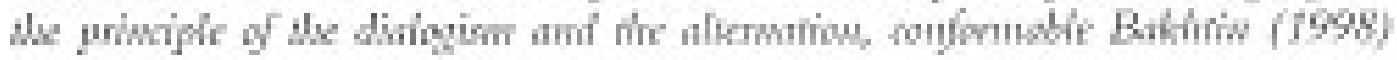

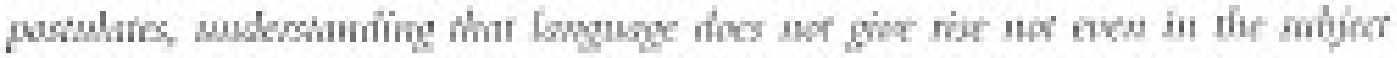

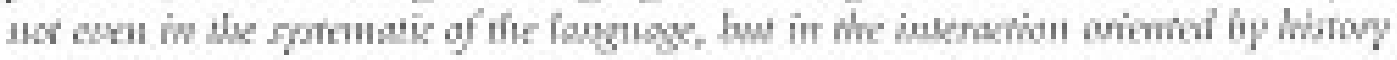

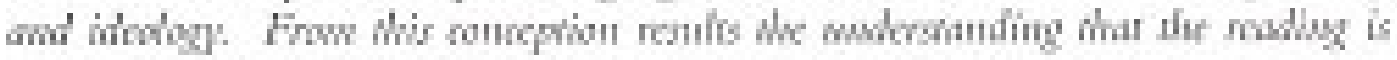

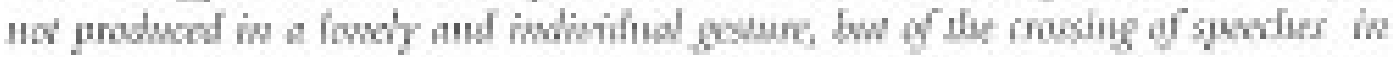

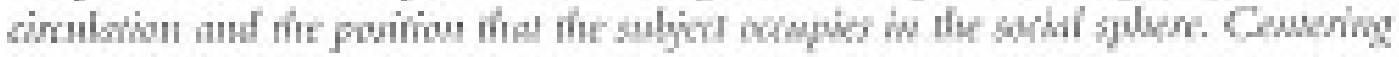

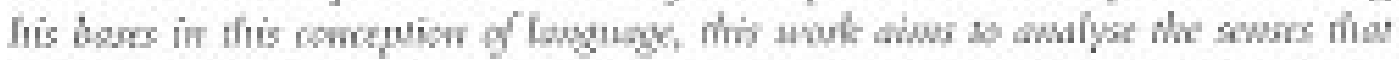

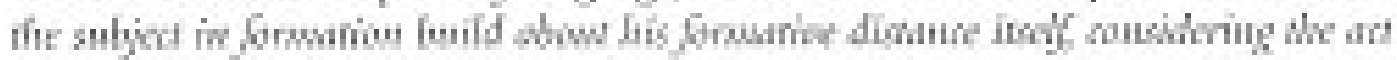

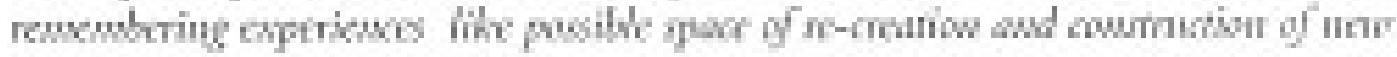
aves it bests

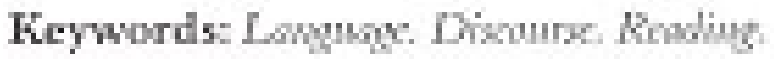




\section{Introdicho}

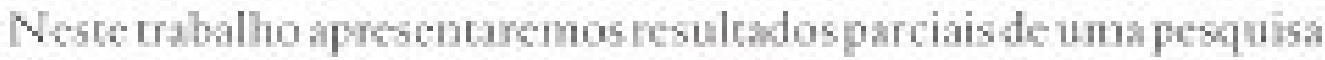

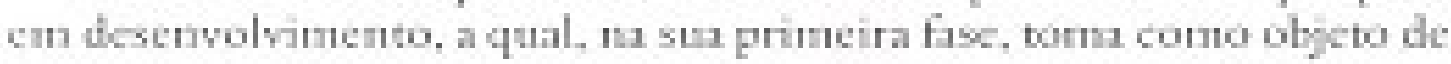

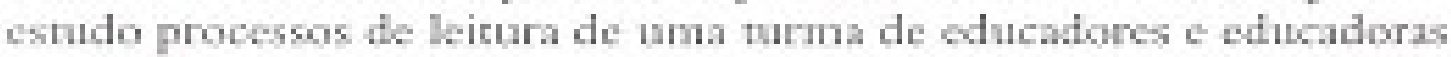

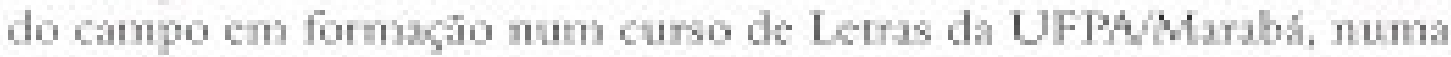
parceria firmada entre LFPA/MSIJNCIRMPRONERA. A pesquisa

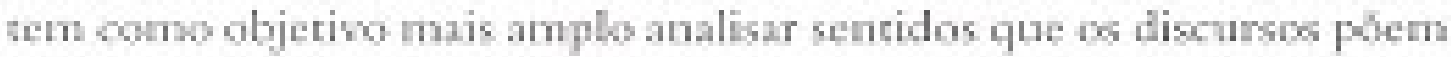
cin circulasto sobre o propris percurso tormating dests sujcitos. cuenderdo a irejtomada de suas experiencias como possibilidade de construcks de nowos sphens.

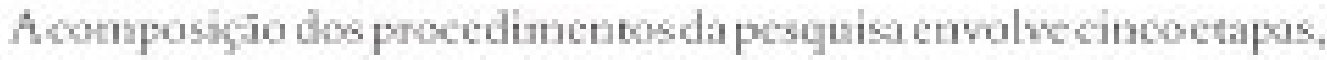

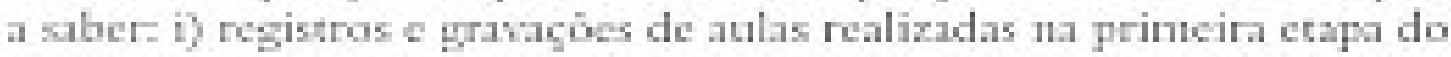

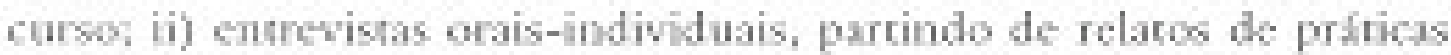

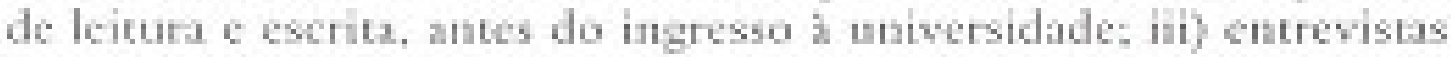

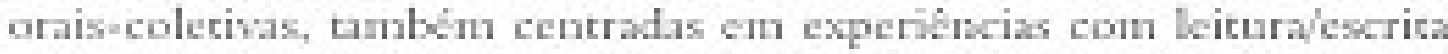

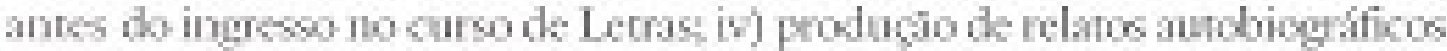
ceritus, astableonds pontos e contrapontos enere diferentes noersentos da

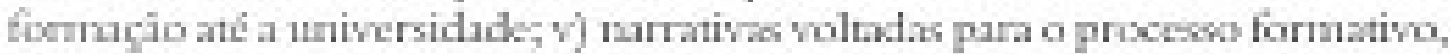

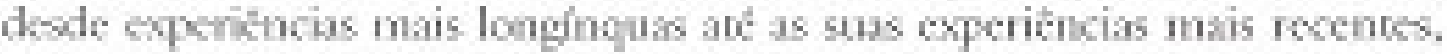

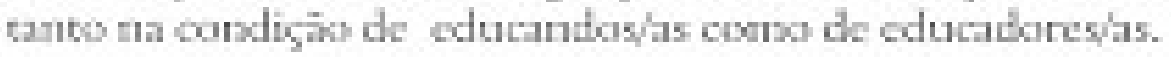

Procuramos articular ó enfoque mebdologico aos instrumentos

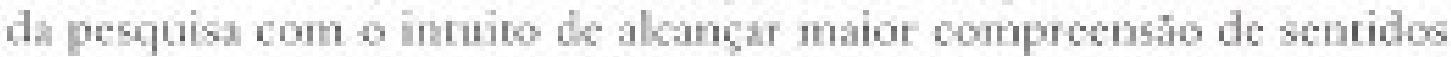
produsidoe pelos discursos dos sujeitosen formacio, no que dis respuito

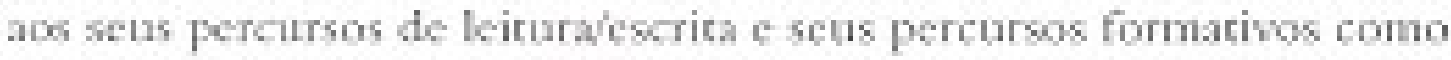

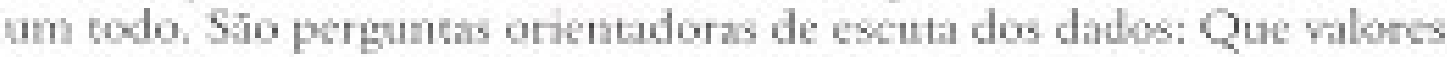
estes sujeitos atribuen a leitura e Aे excritz, considerando o contexto

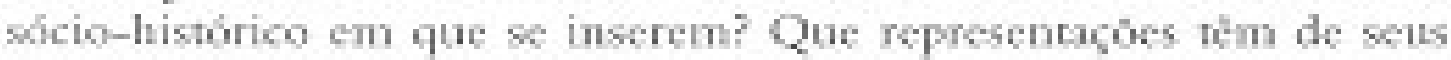
familares no stu proteso de letrantento Como buterpretam a sui

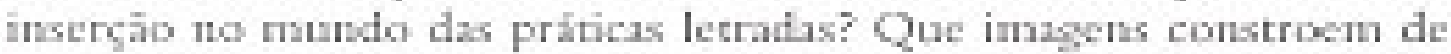

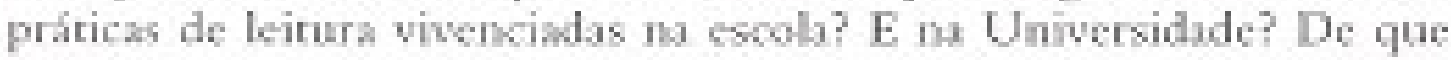
thodo csus experiencias coliboram para (rej)ipaificz gio de suas príticas educziva no campe?

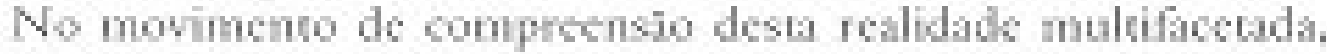
ben cono do valor ztribsido ì eserita na sociedade contemporinea, nâo se pode deixar de perguntar tambum por sentides que shudores

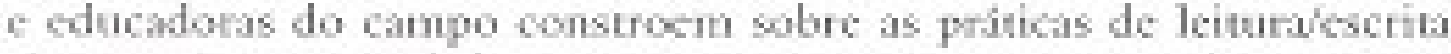
circuscribs as atividades propriz at campo como sapaco de existincia

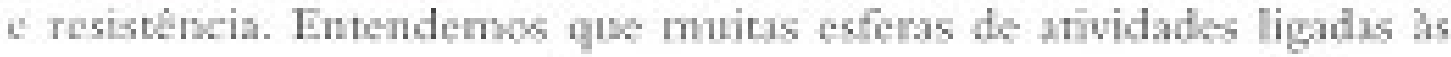




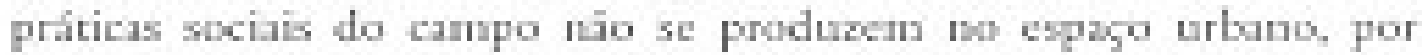

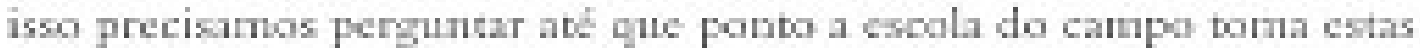
ativades onm refertncias para a ampliach de pricicas aciais de

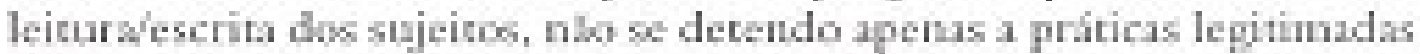

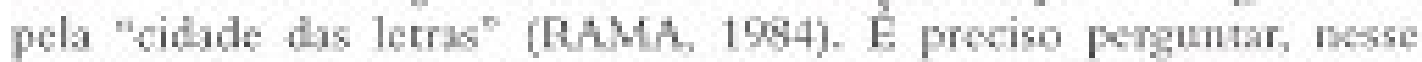

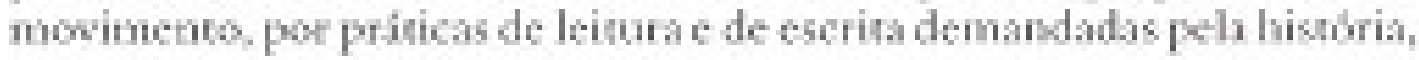

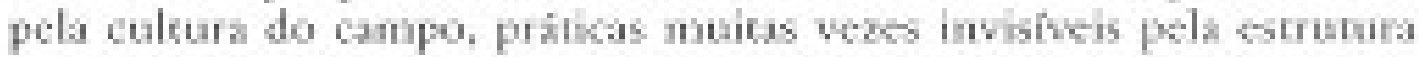

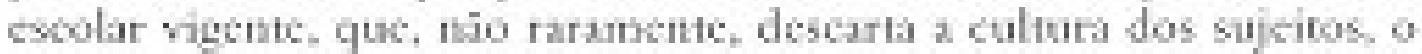

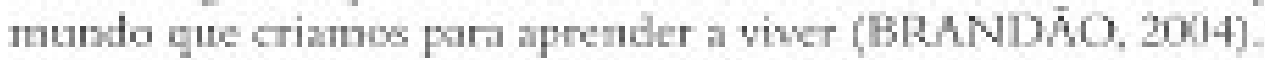

As unativas orais - individuais e coletiva - como mais un dos instrumenes da pesquisa, consticum cspaco de producho de saberes. por meis dis qual se intenci apresder sentidas produzidos tho ato de

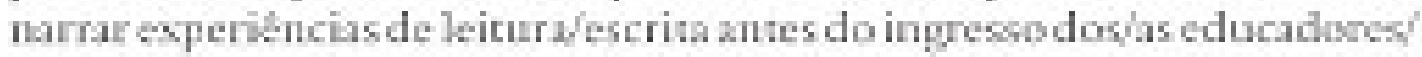

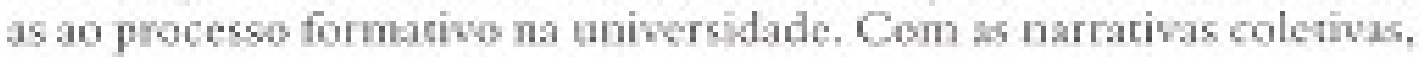

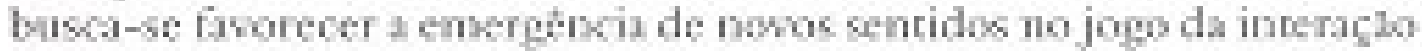

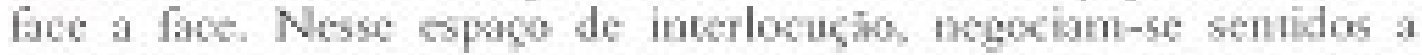

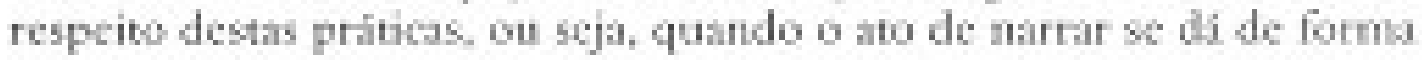

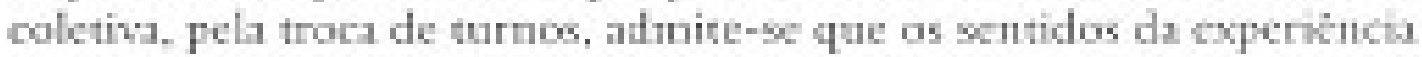

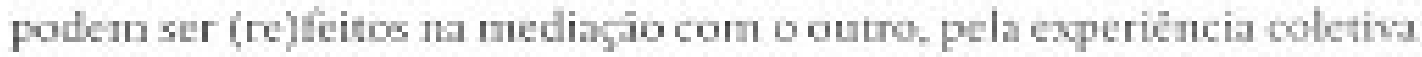
do ato de narrar. Em sintere, a hipotere de que movos scntidos podem emergir nesta moca interlonuisa.

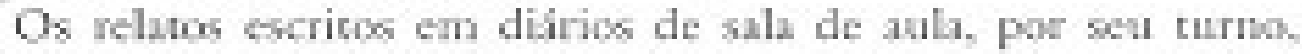

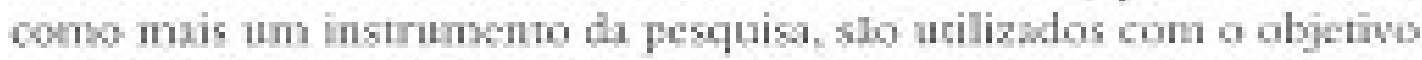

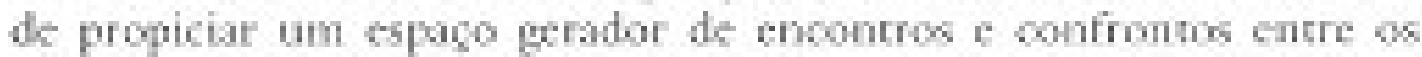

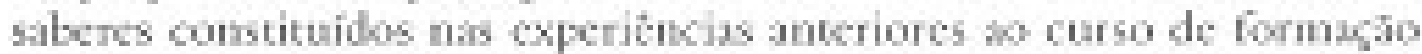

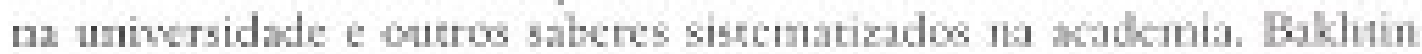

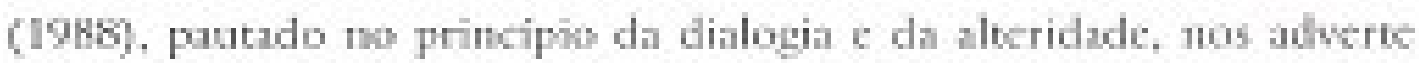

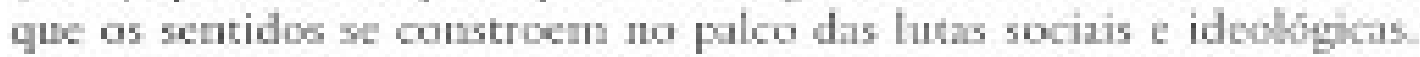

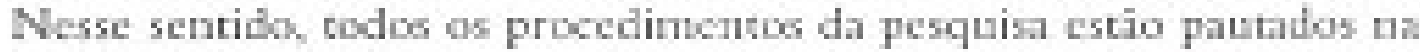

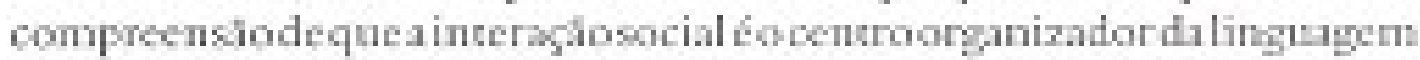
e do senride Wenhum discurs se clahora mo sen irolamento. mas

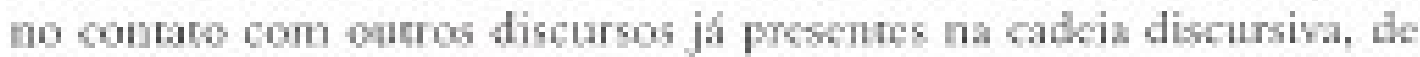

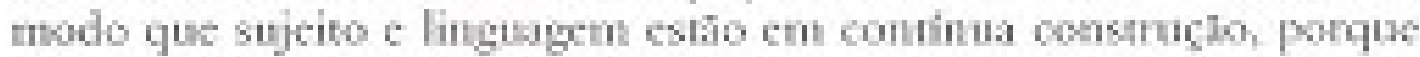

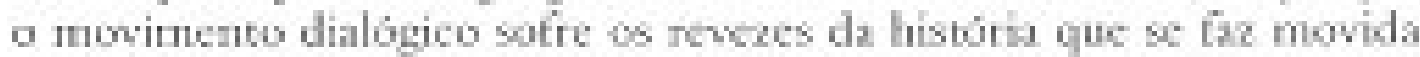

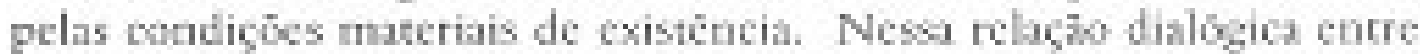

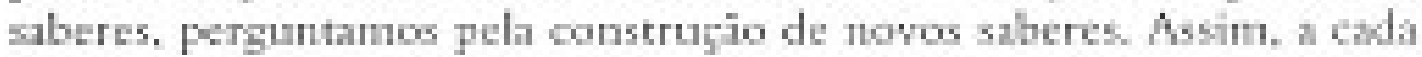

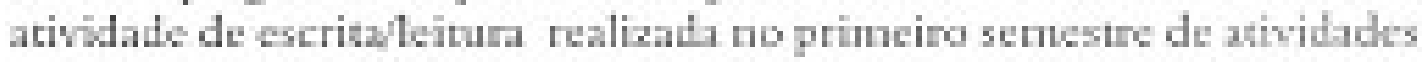

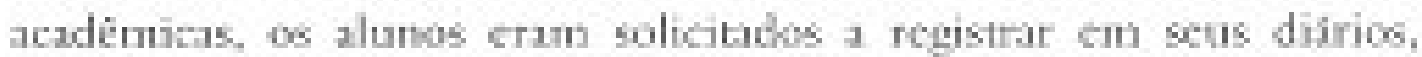

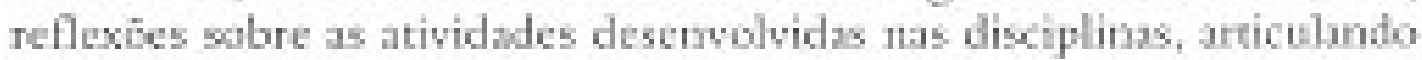




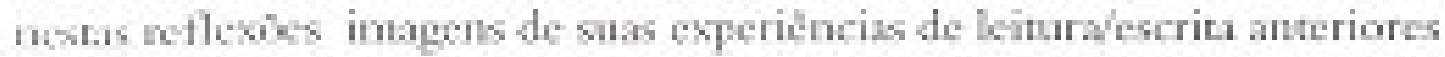

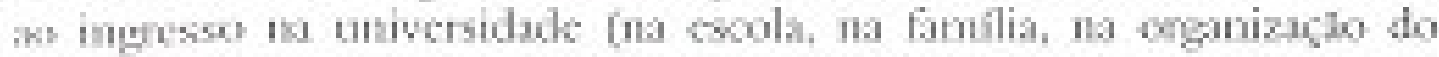

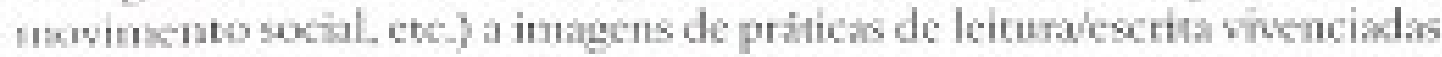

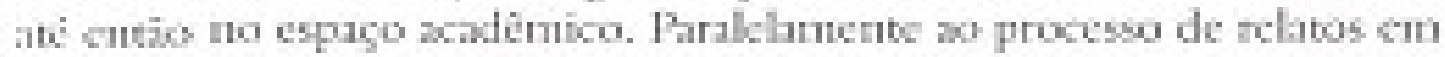

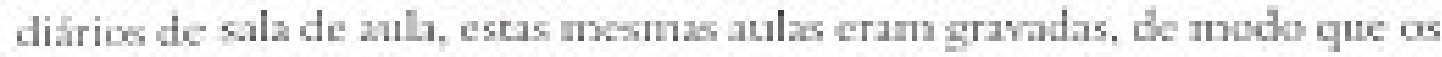

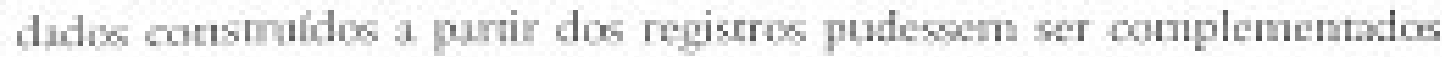

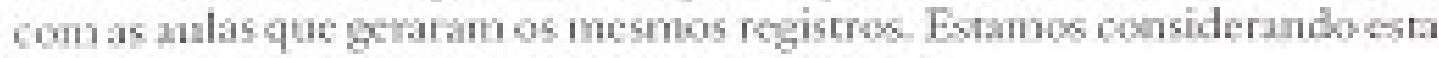

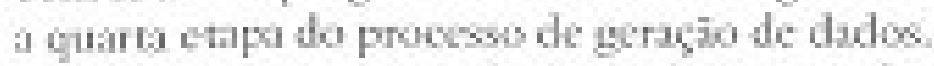

A quinta ethpa de procedinentos da pesquis dic respehto an process de reflesh couthup que as alunos pasam a desenolher

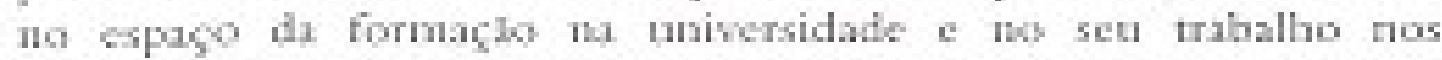

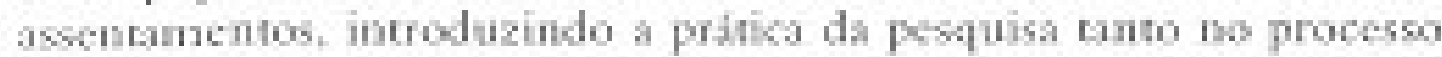

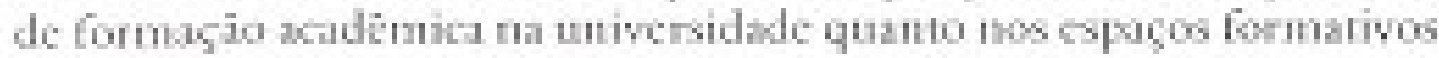

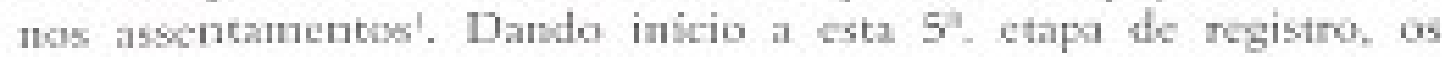

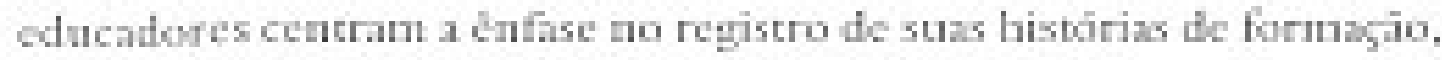

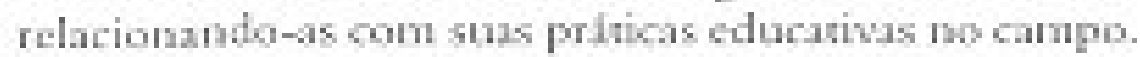

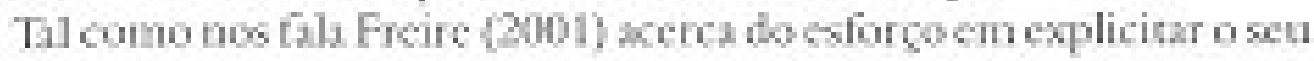

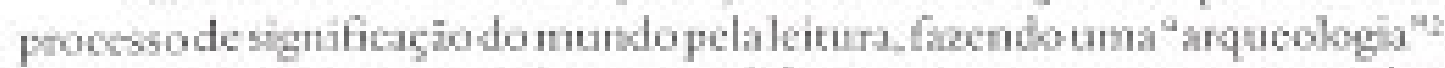

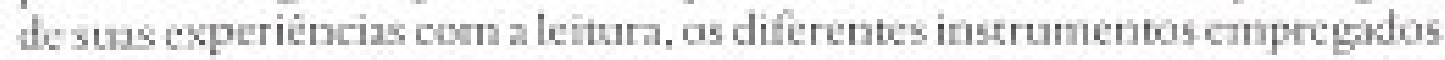

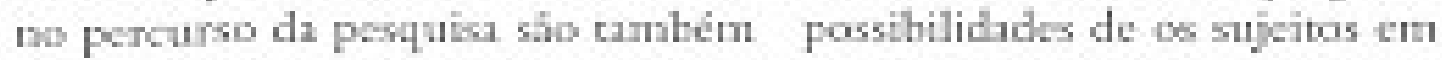

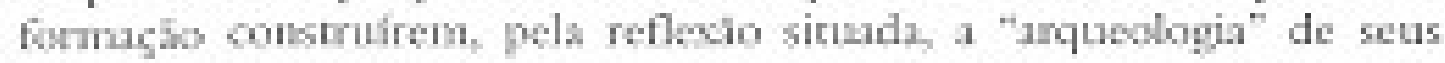

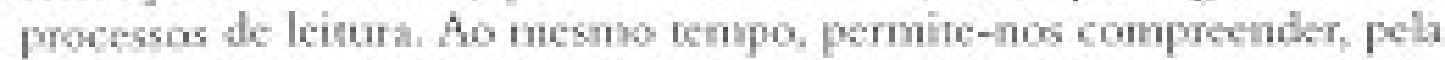

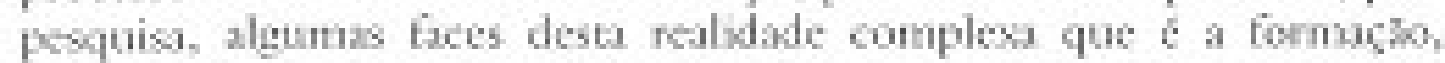

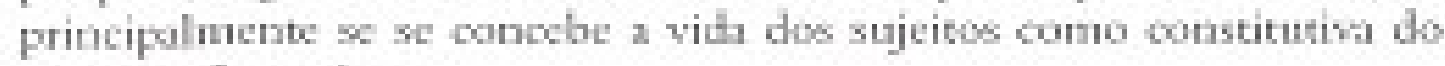
Proeesu formatim.

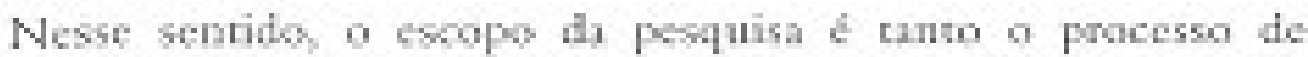

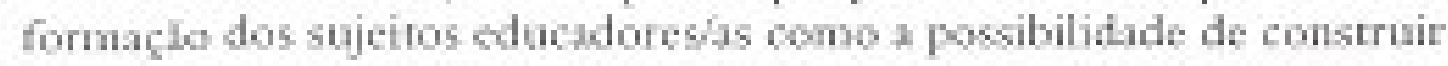

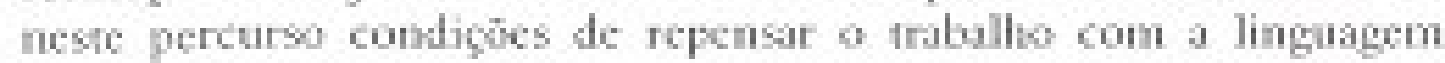

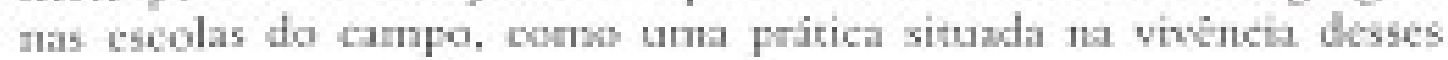

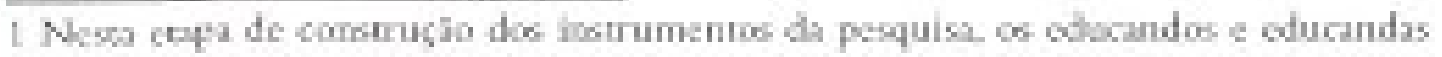

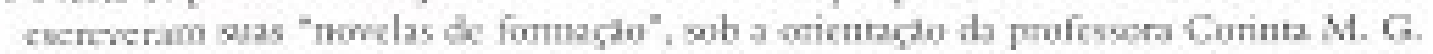

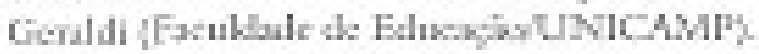

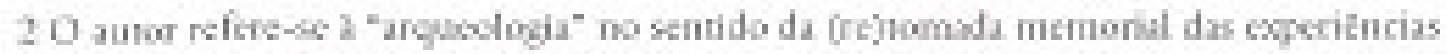

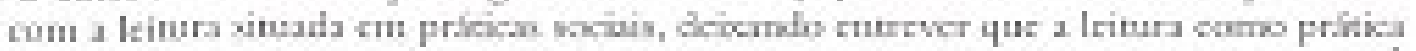

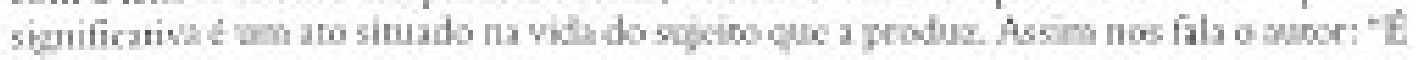

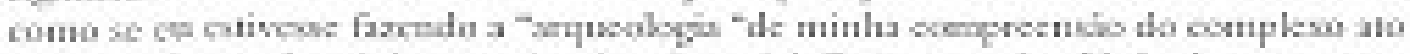

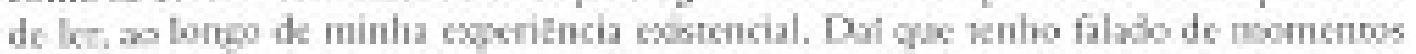

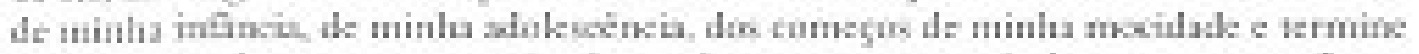

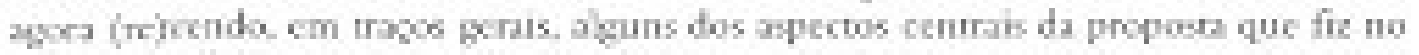

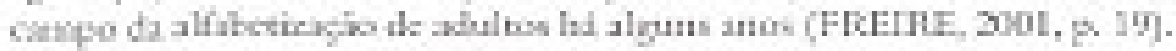




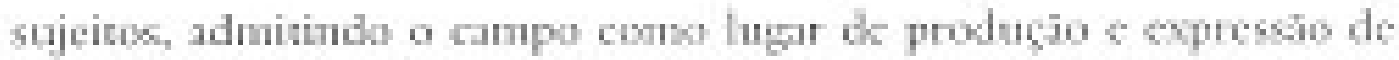

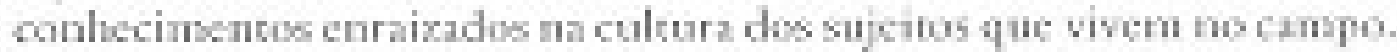

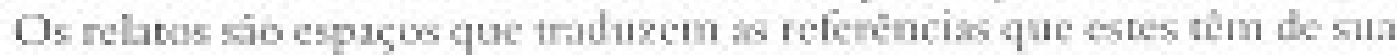

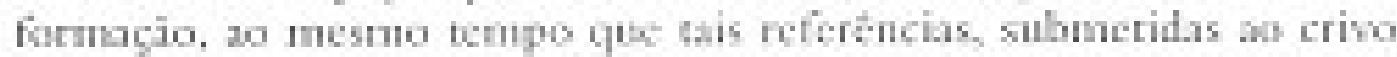

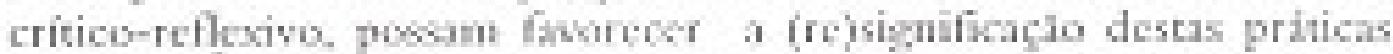

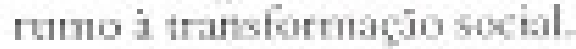

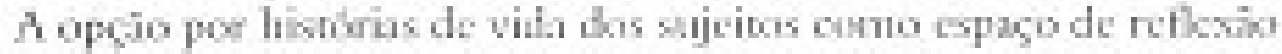

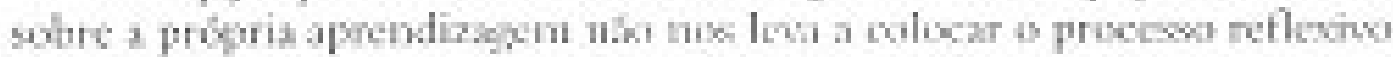

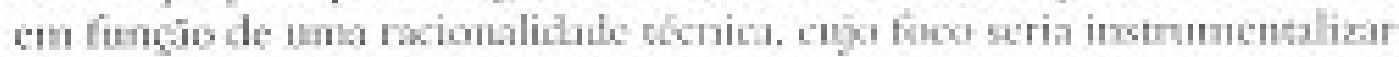

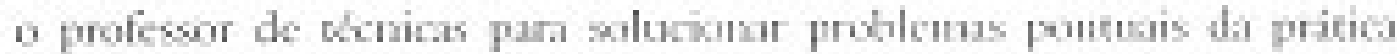

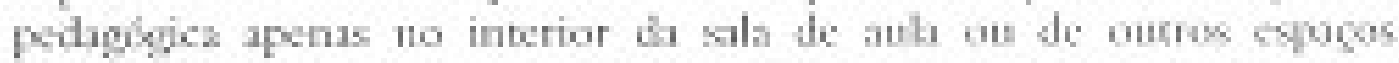

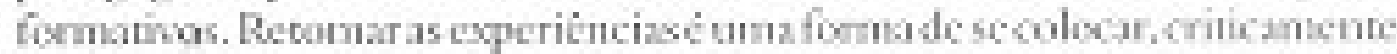

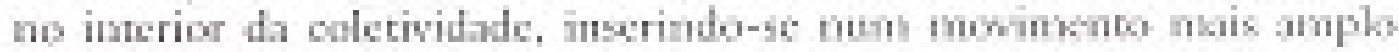

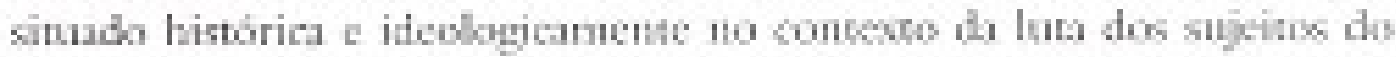

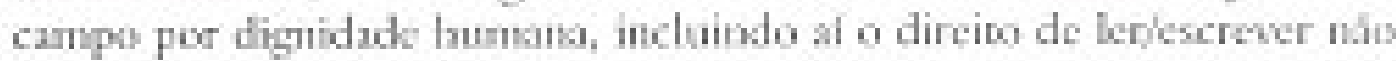

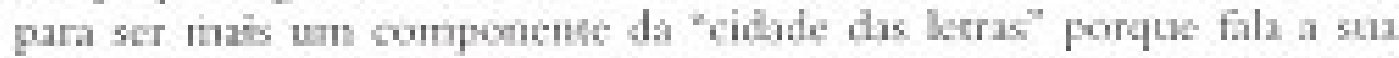

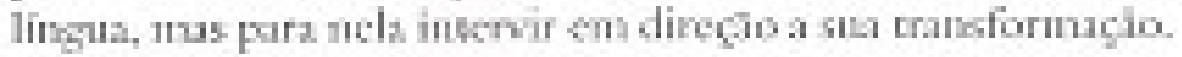

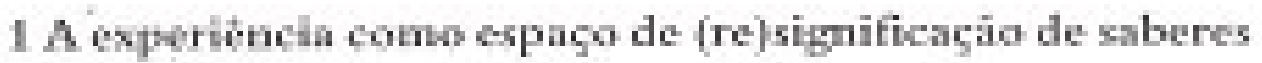

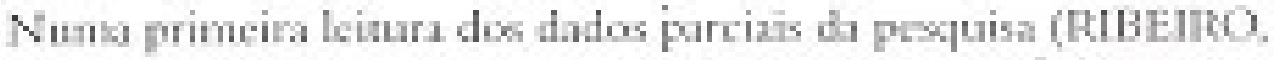

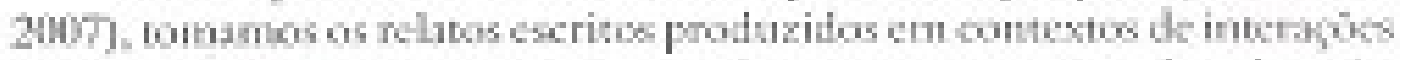

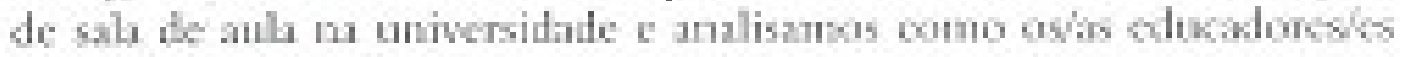

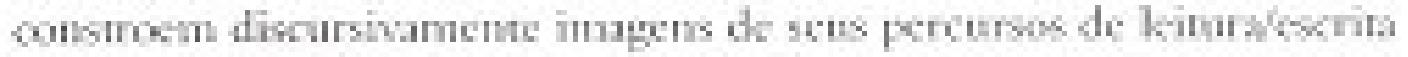

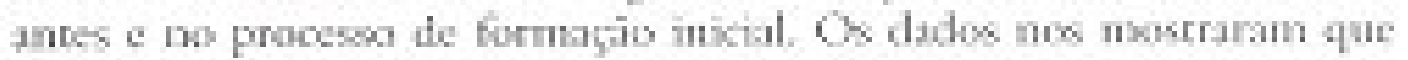

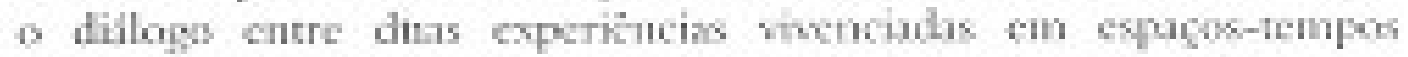

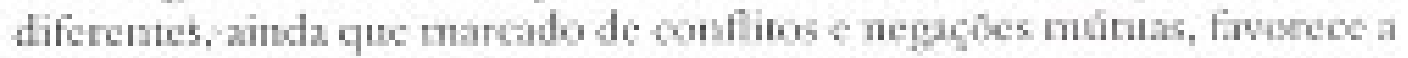

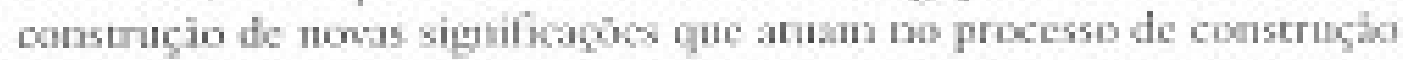

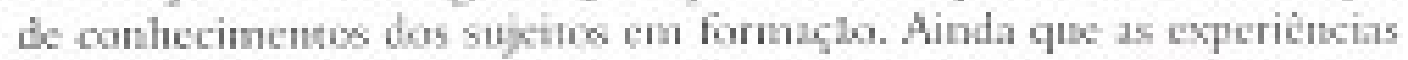

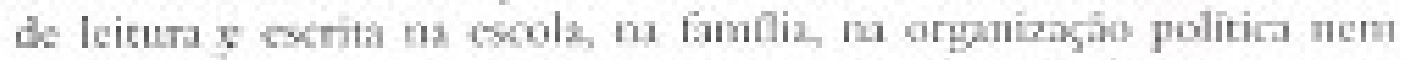

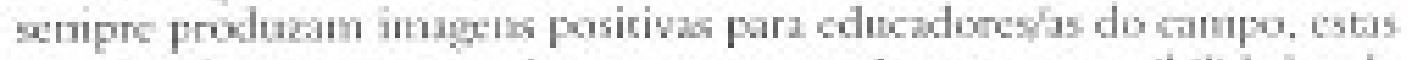

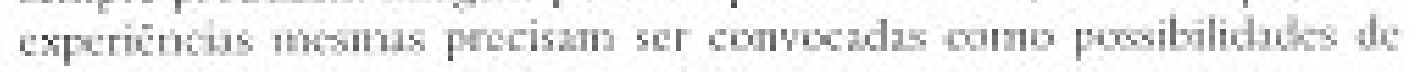

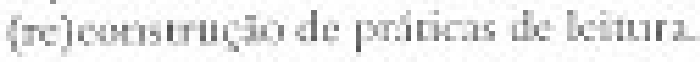

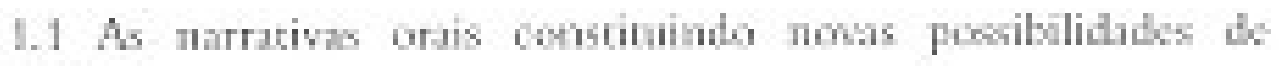
mimperisio

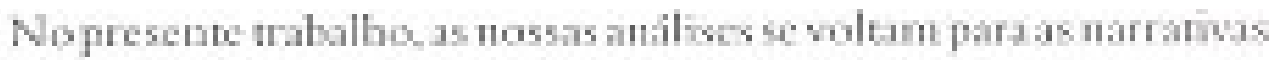

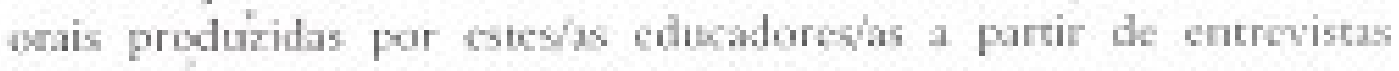


realizadas durante a prineira etapa do cuso. A leimu wostitui of tema centril destes relaces memorizis.

Optande por uma metodologia de naturea qualimina, as

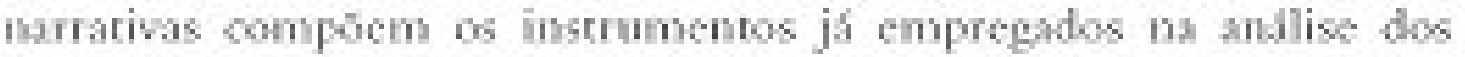

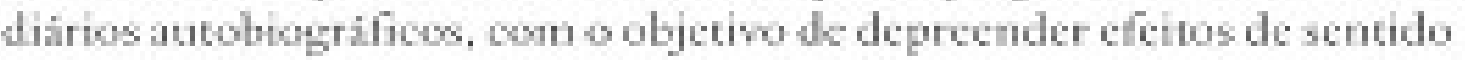
produzidos sobre os educadoredas en formaço acenta de sus priticas de leitura antes c durante a sua formaço inicial me universidade.

Adnicimos com Larrosa qụe

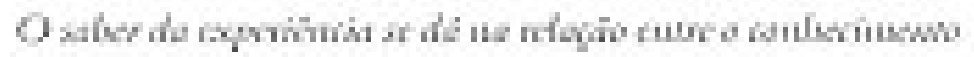

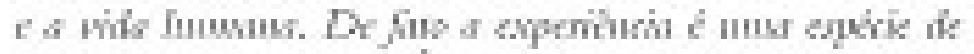

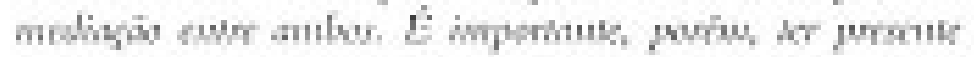

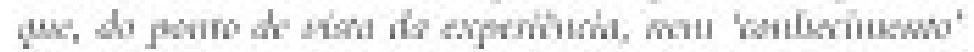

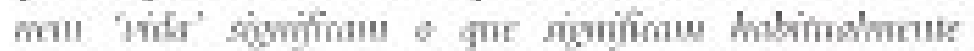

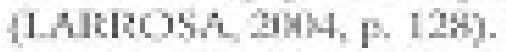

Pura satom, o saber fundado ua experiencin, antes de ser wn saber desprovido de conhecimeno, deve ser penado cono um saher diarinto tho saber cientifico, do suber du informsho, da rocionlidade edenica c instrumenal, mas un sber que se dil na relacio do conhecimento

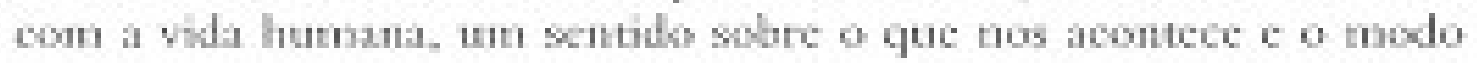
como wamos respondendo em fhes do que vai nos acontecendo. Se o

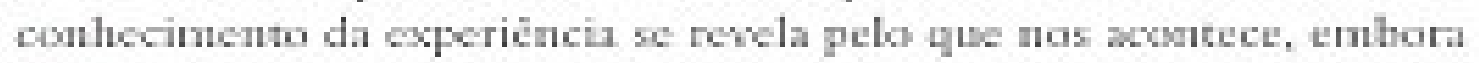

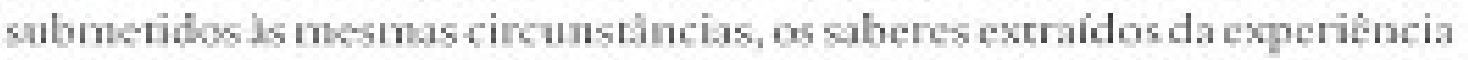
de cuda un sio ro henorogeneos quanto a relayo que os possibilita.

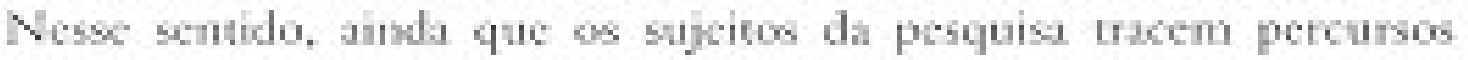
semelhantes de leitura, esses experibuciss se particularizan no modo de seren significadas en cada marrative. Obvimnente que os dados siagulares remerem as condicos hiskricas da elase seial submetida

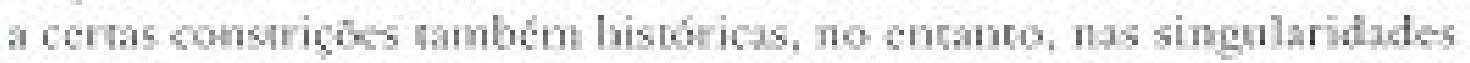
destes gestos identificamos tracos da subjetividade co da pluralidade de sentibleg no interior da coletividate.

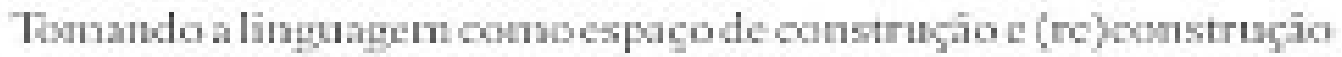

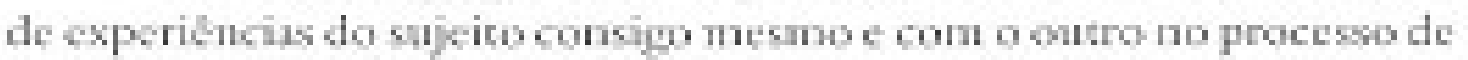

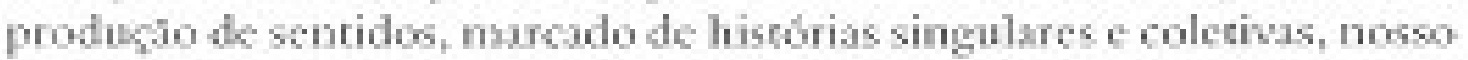

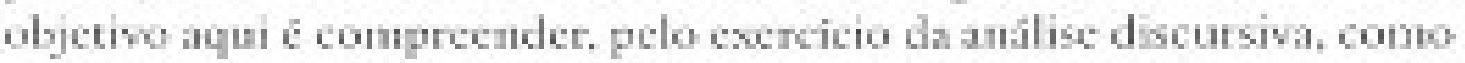

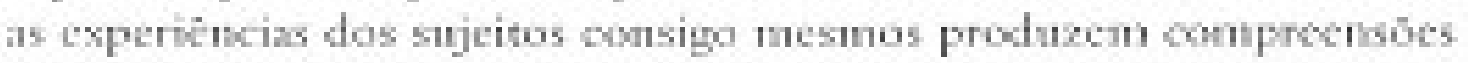




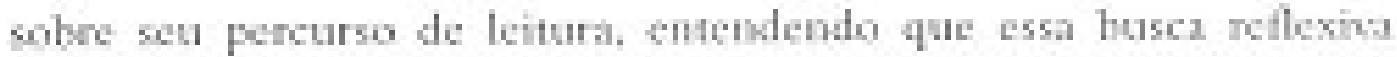

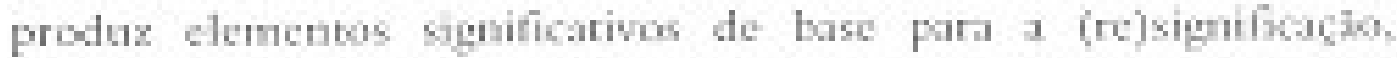

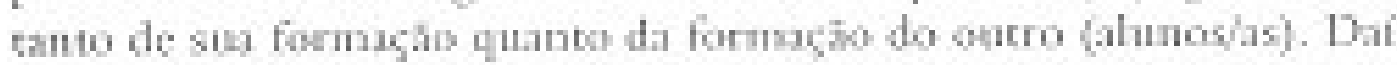

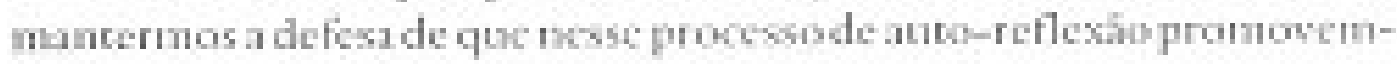

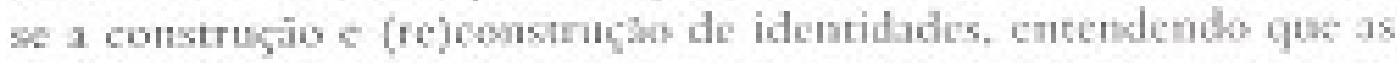

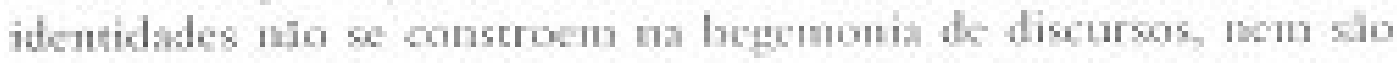

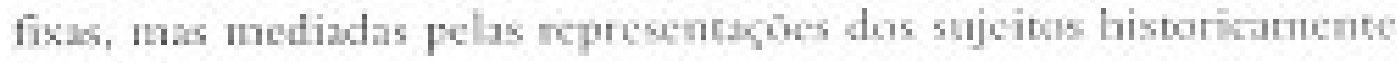
situados.

\section{$2 \mathrm{~A}$ linguagem como acho dialbgica}

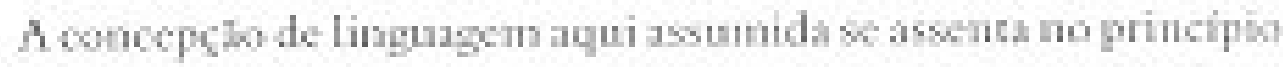

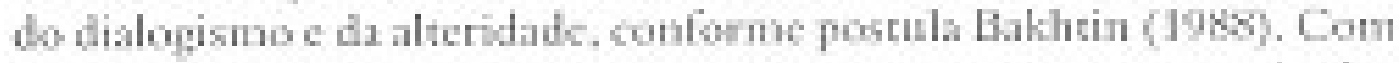

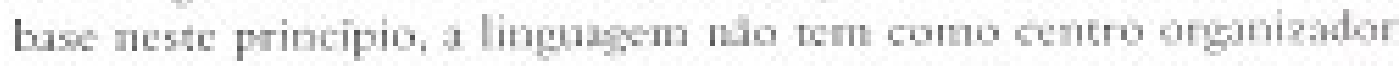

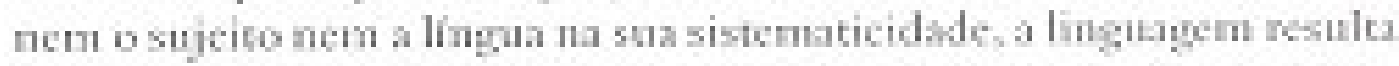

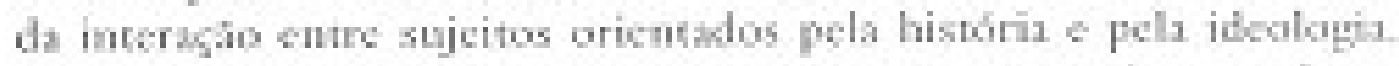

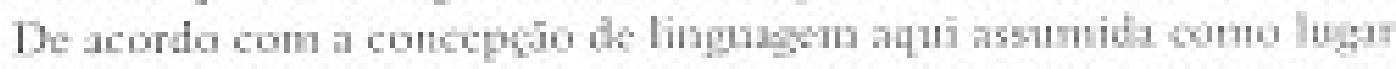

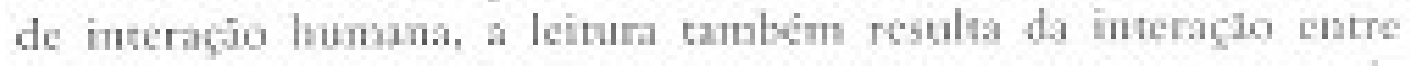

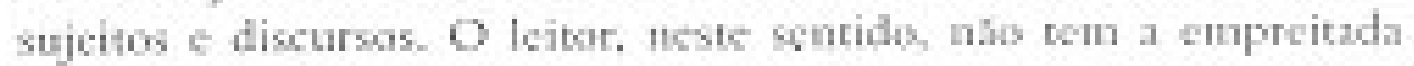

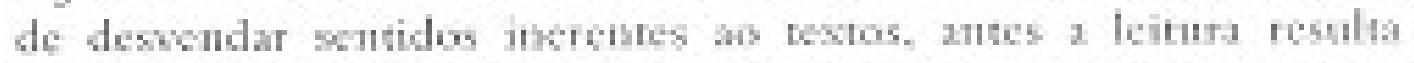

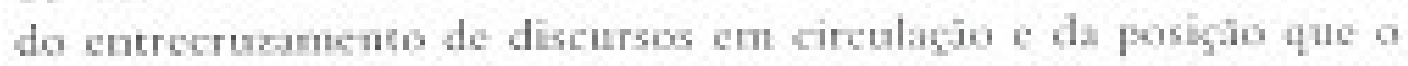

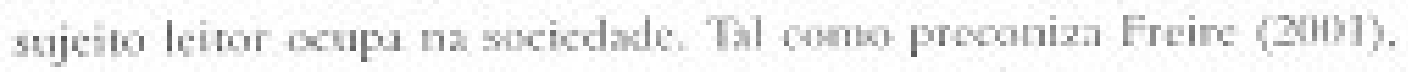

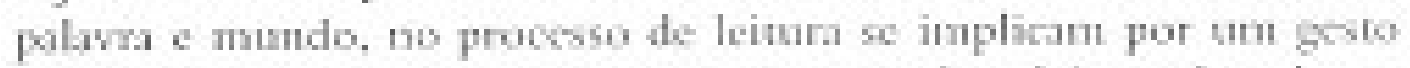

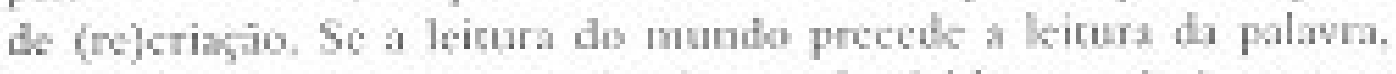

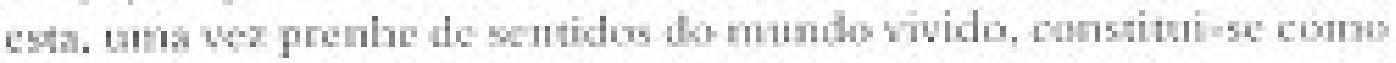

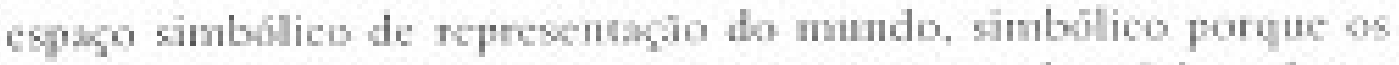

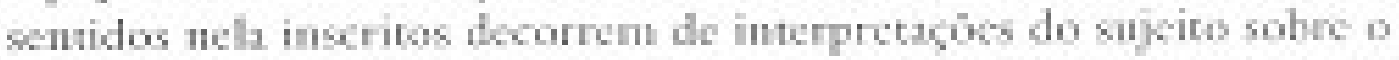

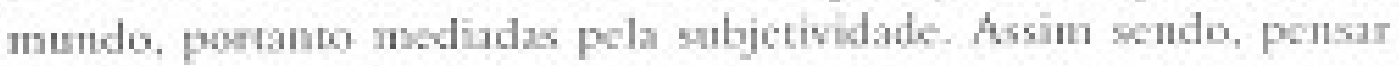

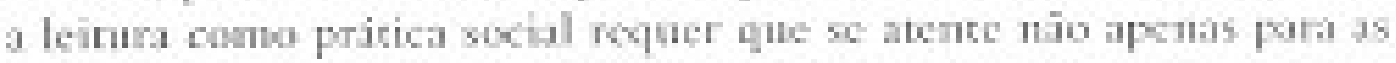

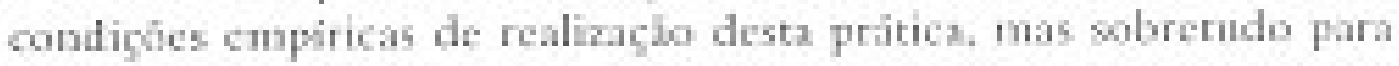

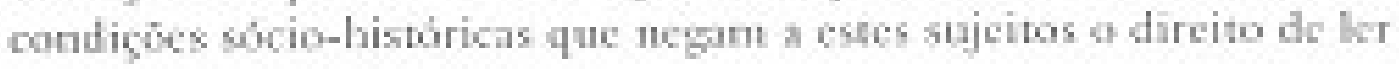
0 thusa cumbin pelle estritit.

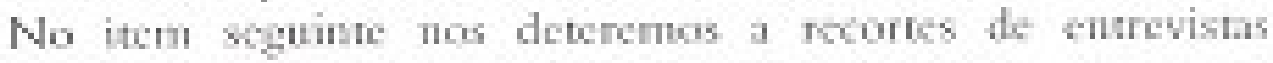

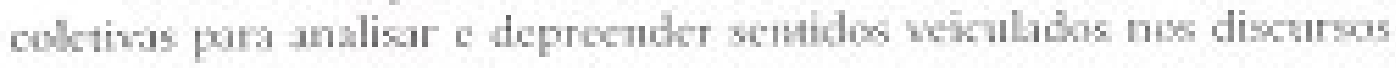

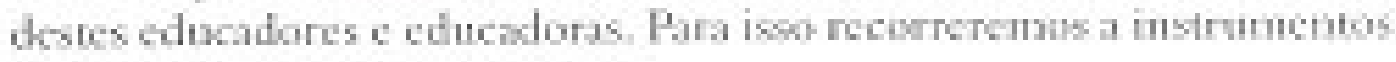

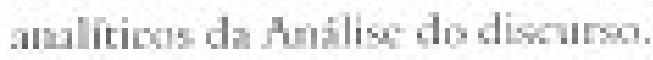




\title{
3 Matrizes discursivas veiculadoras de sentidas sobre memorias de leiturn
}

3.1 Aprença da tunilia em procesnce de leitura

\author{
[1]

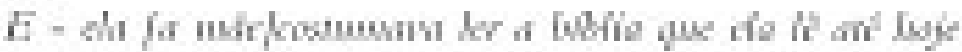

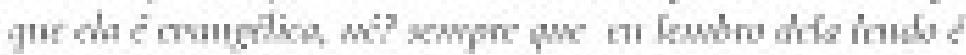

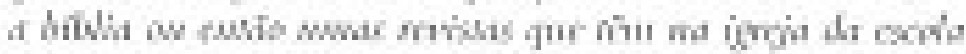

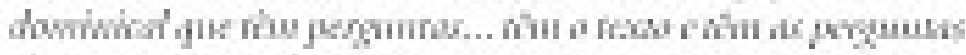 \\ do rupe b Dbj
}

\section{[2]}

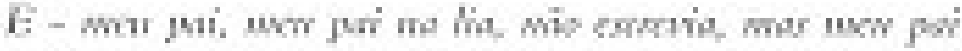

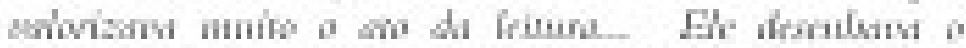

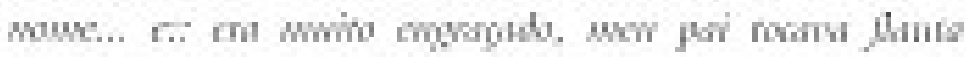

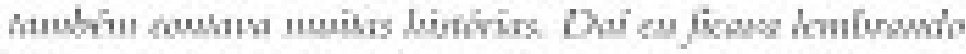

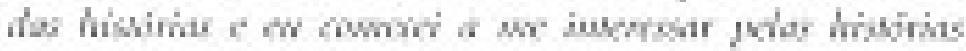

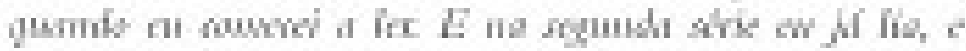

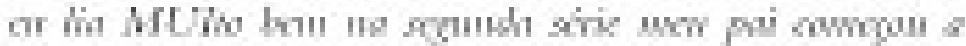

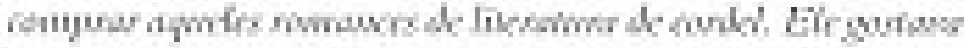

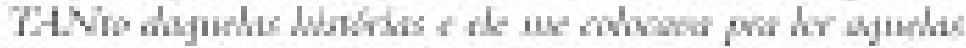

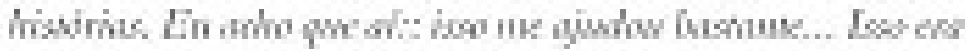

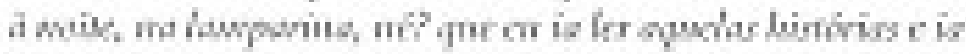

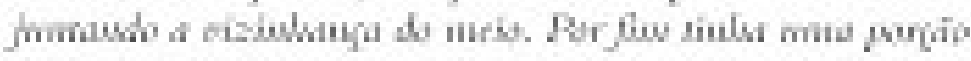

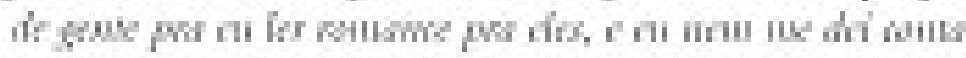

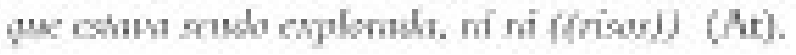

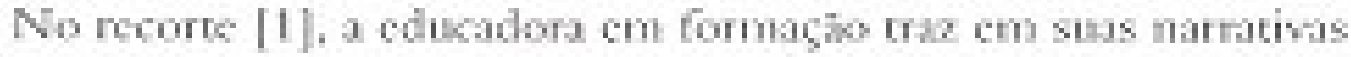
suis tumbrias de leitura a partir de una pritica social experenciadi por

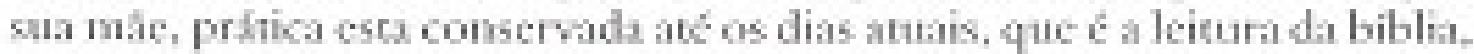

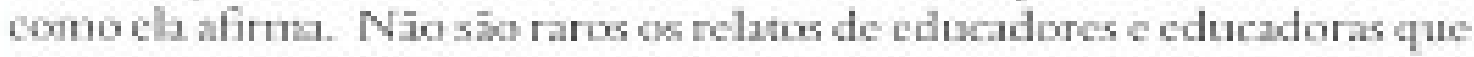
apontan a preseng de nembros da famila mediando príticss de leitura. notidimente a mic. Fste $t$ un dado interssante par compresuiemos

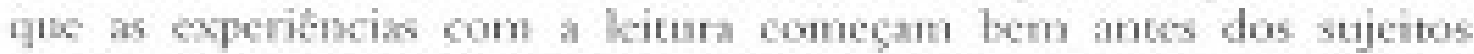
denerinen o espaco escolar. No cntanto, una wes subnetidos so ritual

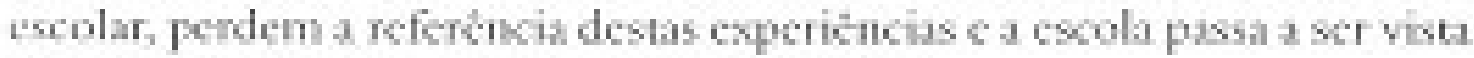

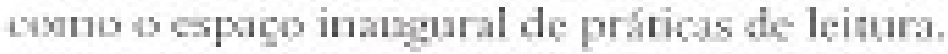

Eni [2]. obsera-se a presenga do pai inviands o contato de At wm a leiture. Ben se oberw pelus príricas excrias, ama walorizacho 


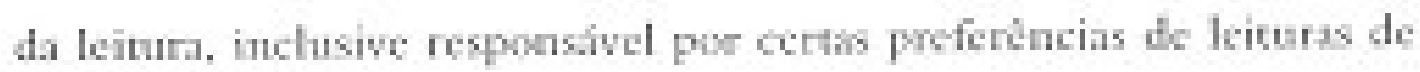
An. na vida adulia.

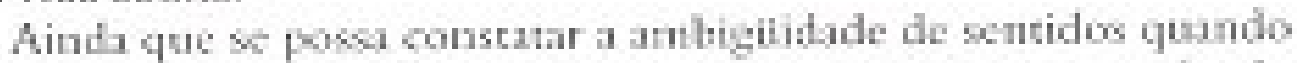
Ar dix que na segundi strie jo lia e lia "MUTro hem" - podendo

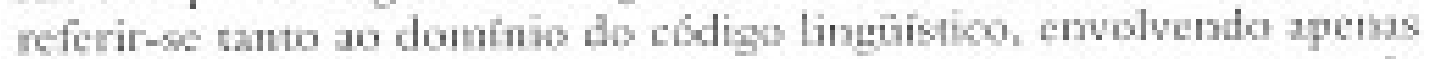

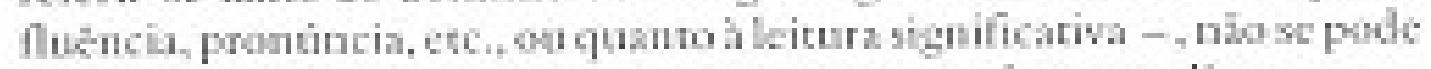

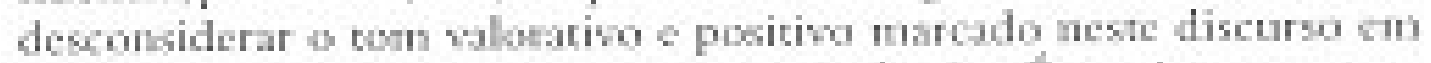

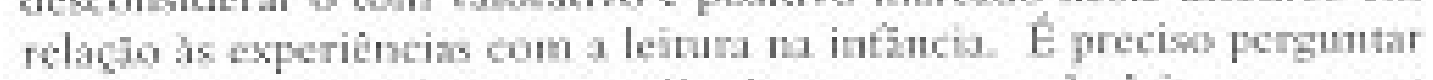

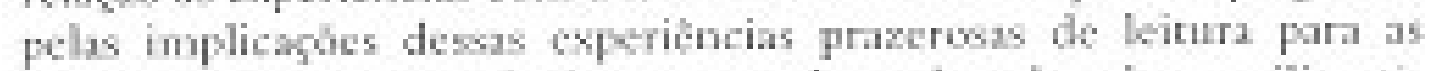
prithes de rida acuis de At. wowh sducanda, cducadora, milicante.

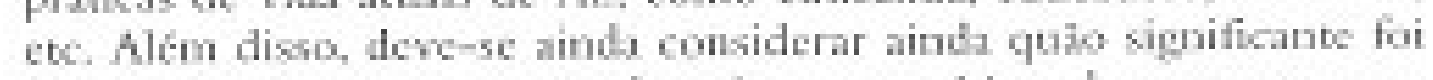

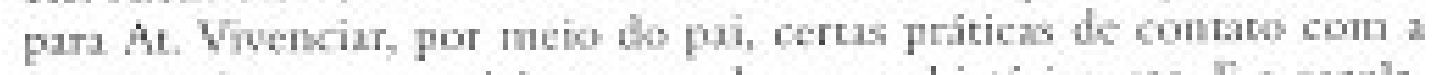

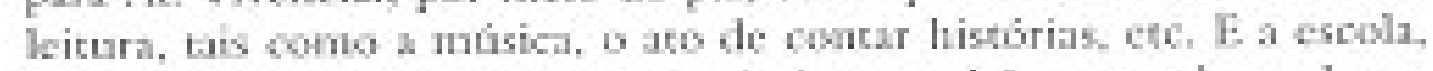

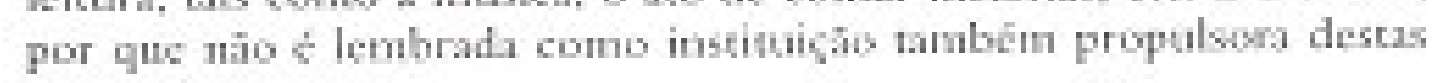
práticas:

\subsection{Pepresencigos de csola wono agenciadora de lentura}

Os dados nos apoun que a escole é representa cm thibos

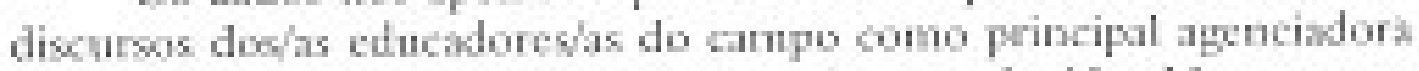

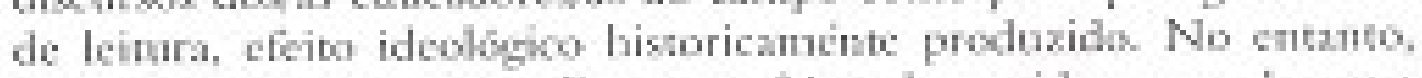

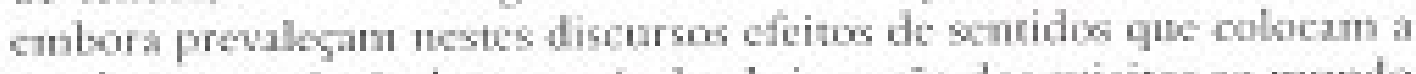
sobla com principal repotswel pela insersio doos sujeins ao mundo

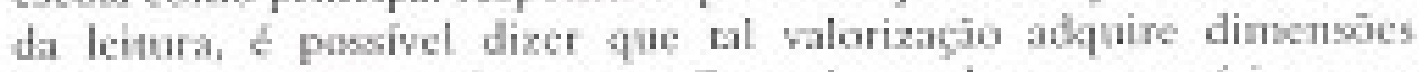

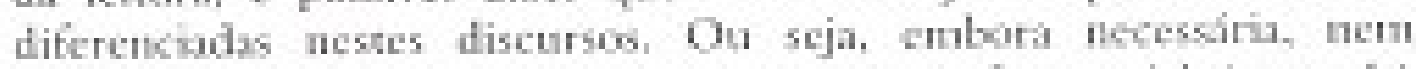

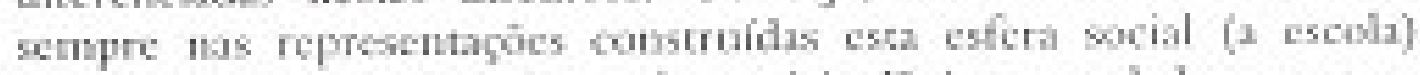
atende posinimene as dcomils seciais. Dai que os dedis aponem

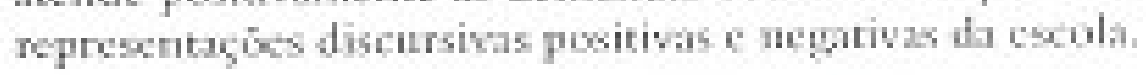

\section{2 .1 Represtrtagles poritime da duda}

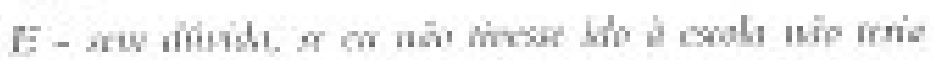

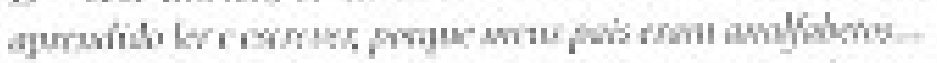

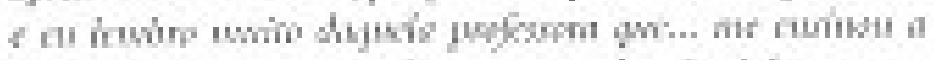

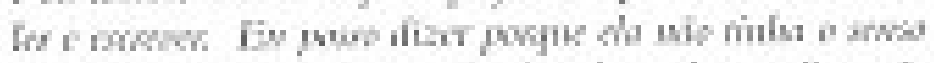

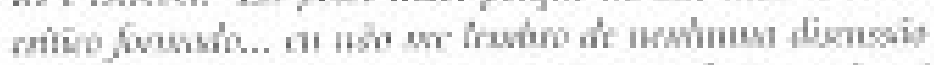

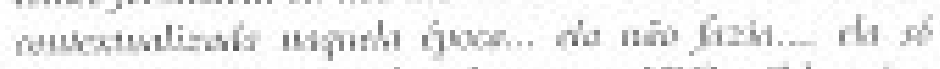

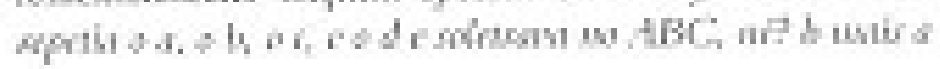




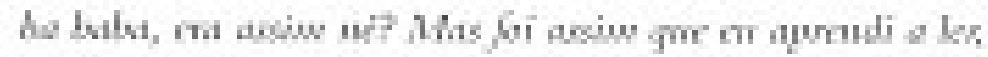

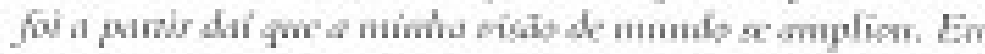

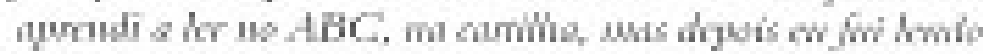

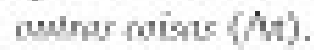

\section{[-1]}

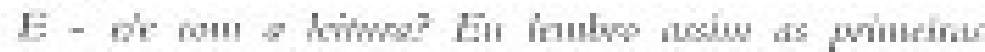

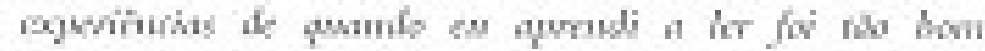

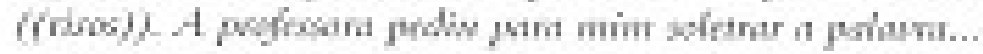

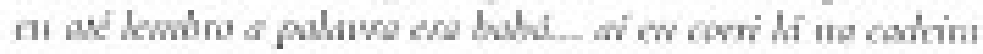

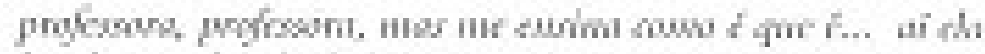

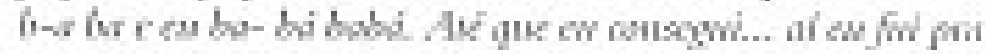

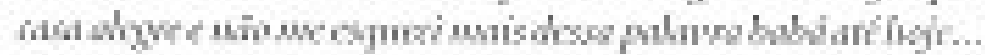

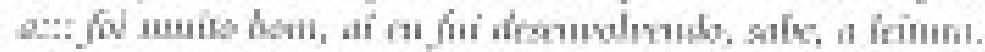

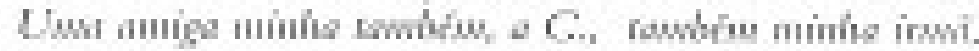

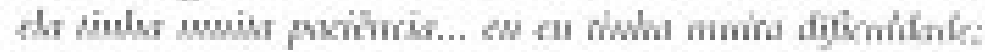

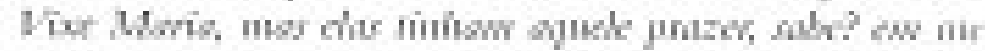

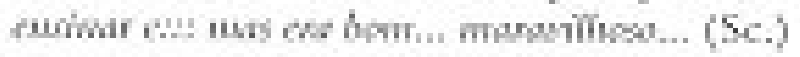

Os dwis recortes acima se inserewent en uma repias discurbiun

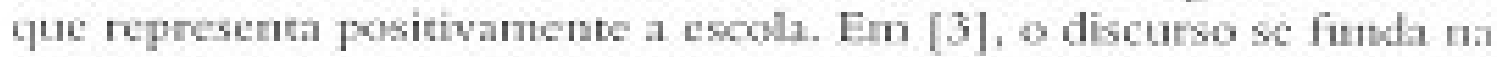

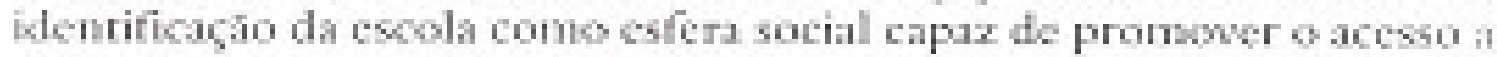

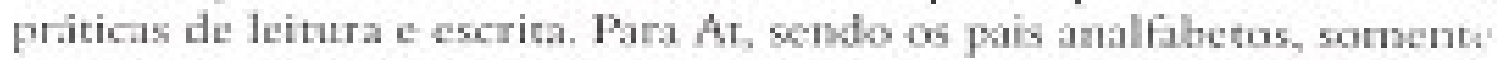

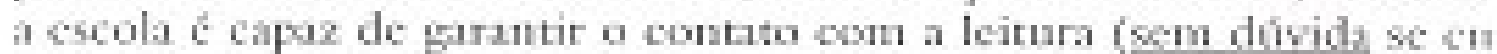

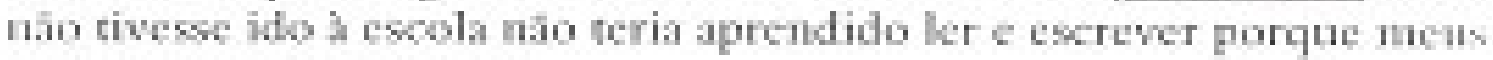
pas cram analfabetos...j.

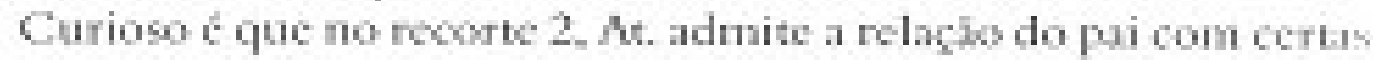

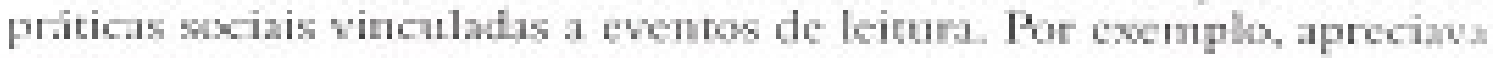

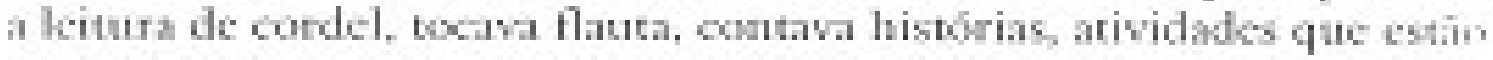

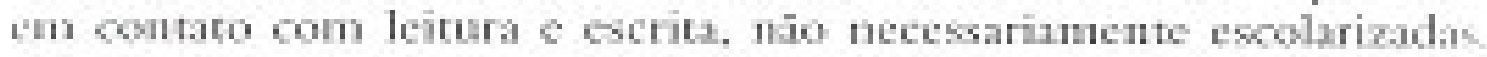

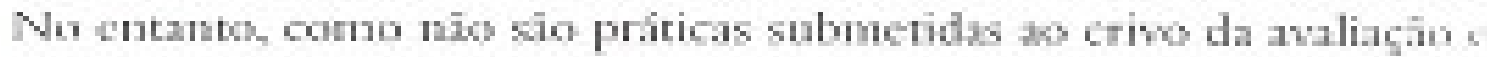

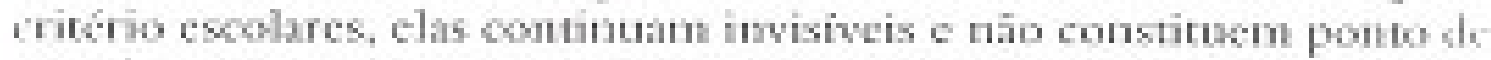

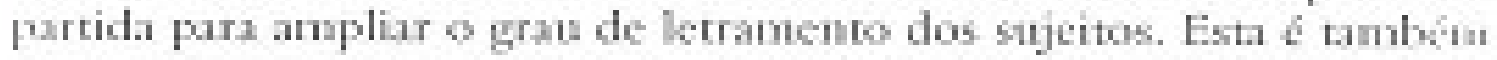

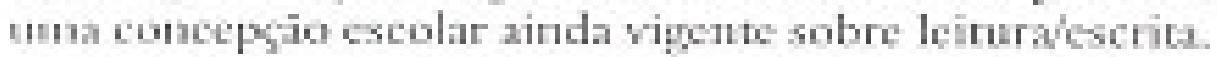

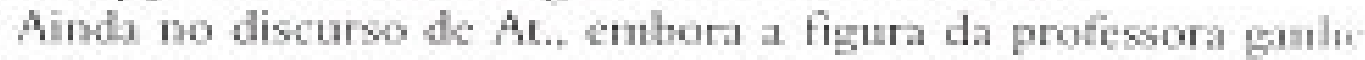

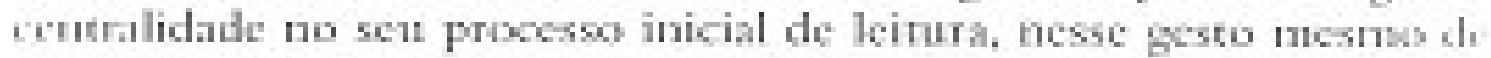

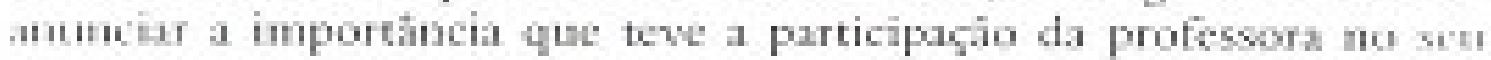

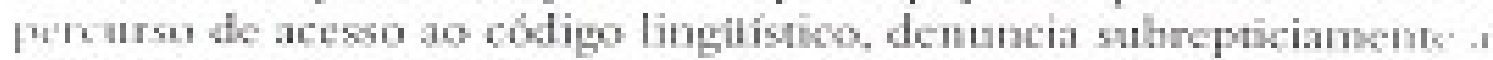

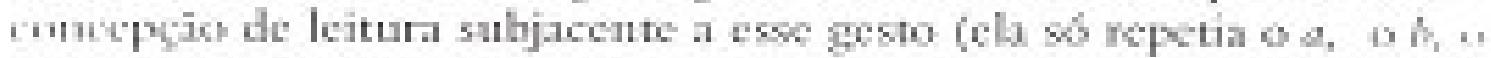

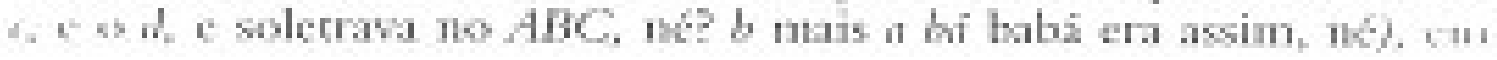




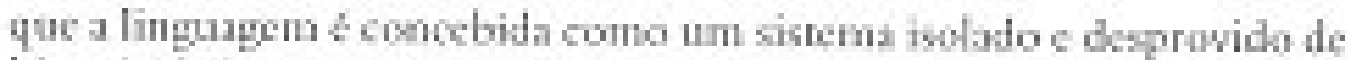

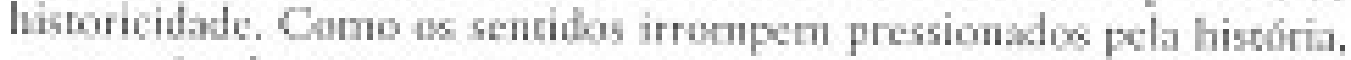

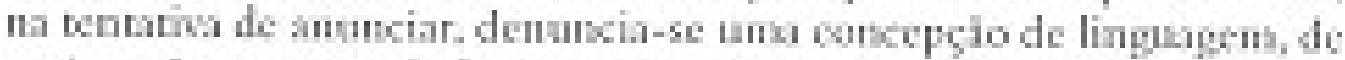

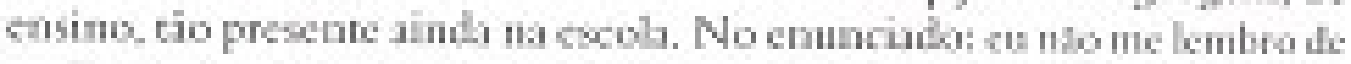

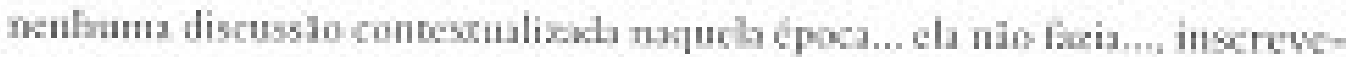

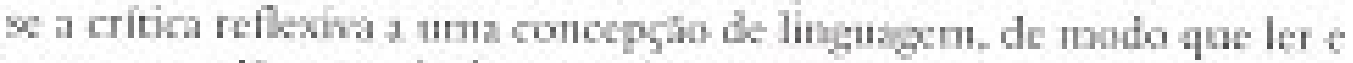

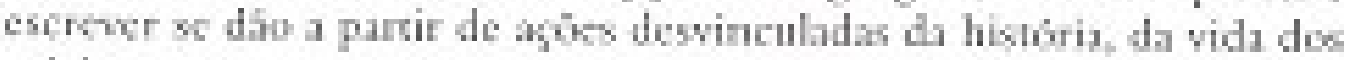
Fujeisos.

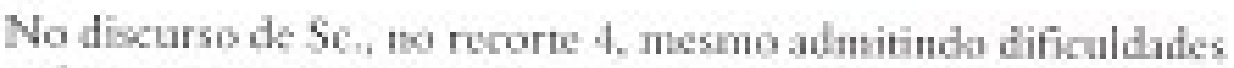

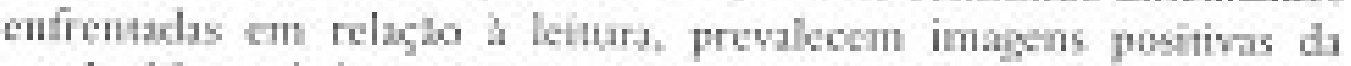

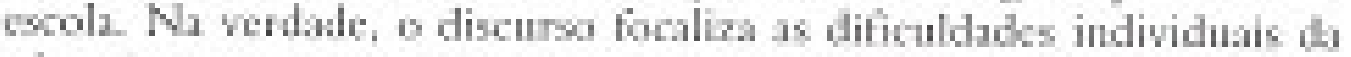

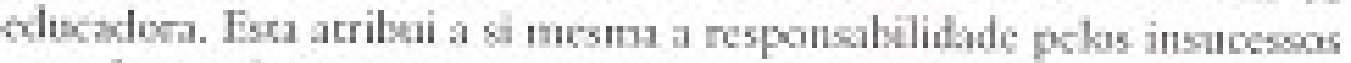

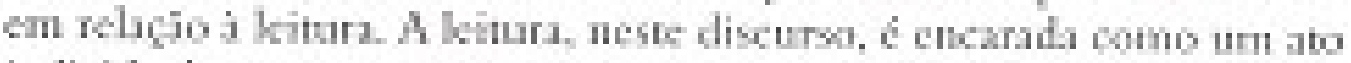

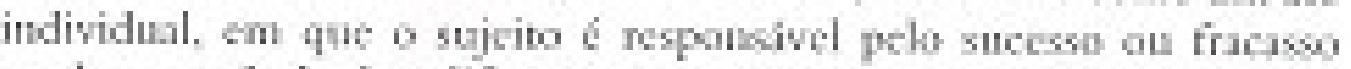

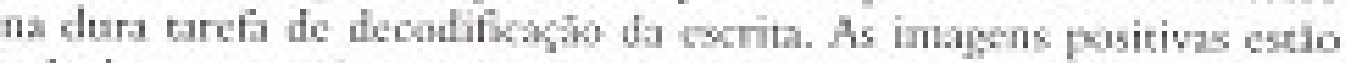

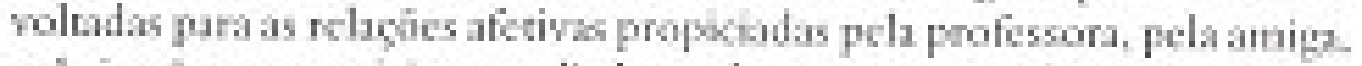

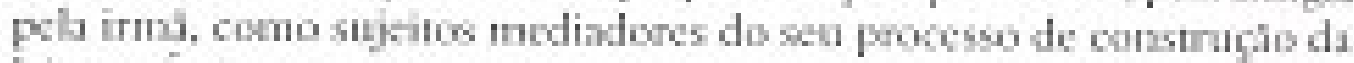

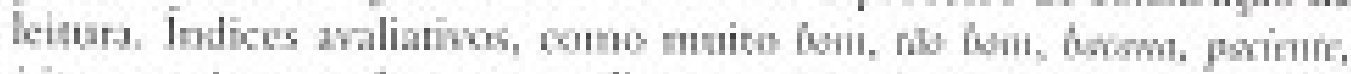

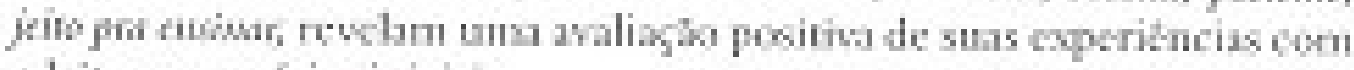
1) Kiturn nas strics inicus.

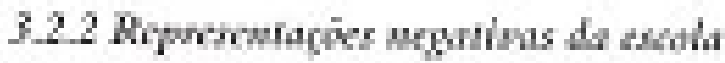

\section{1}

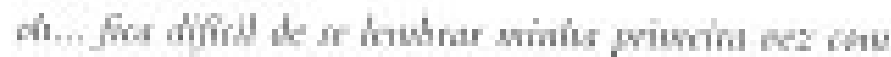

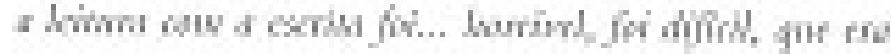

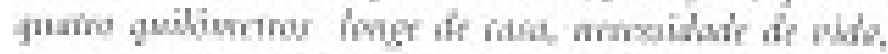

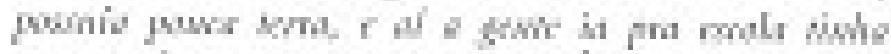

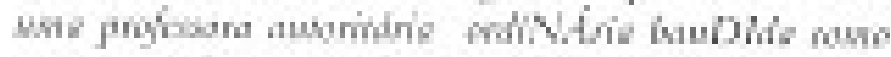

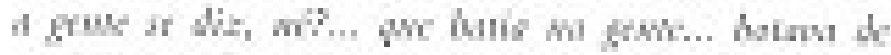

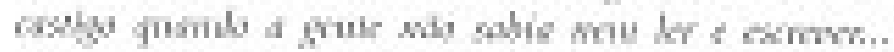

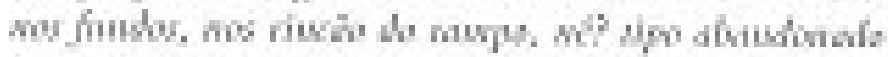

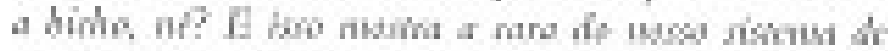

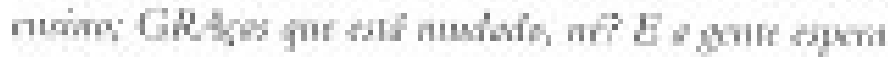

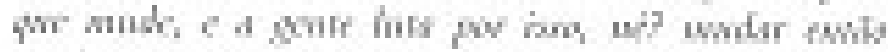

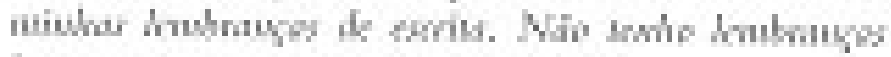

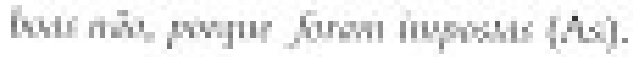

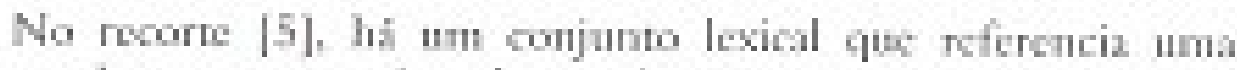

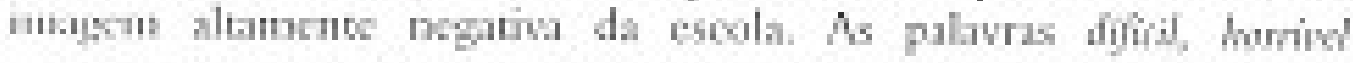


uvidencian cat representacho negriva sugerindo a recust do supeto

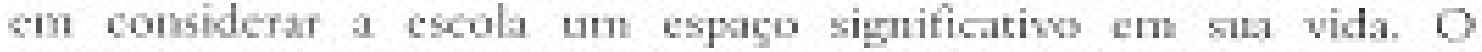

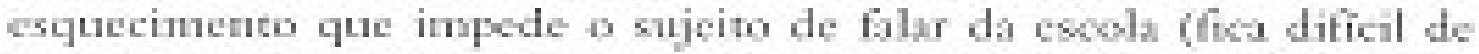

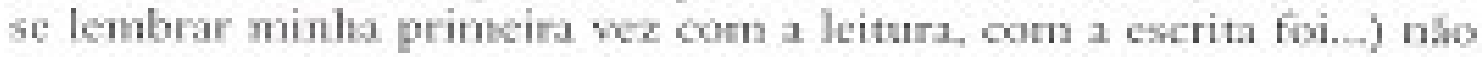
E de ondem mental, mas discursiva, porque lembraiffalar cotresponde

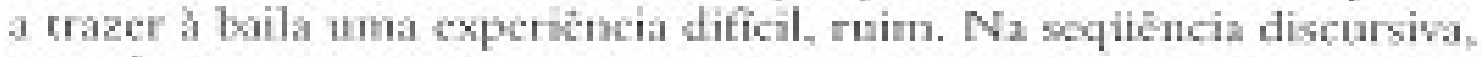

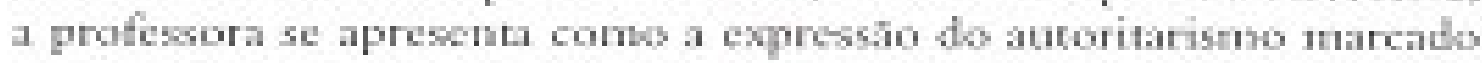

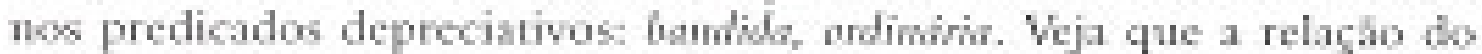

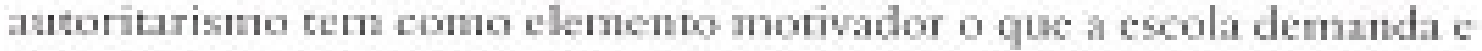
o que o duno responde on felaçio a esta demanda, de tal modo que a

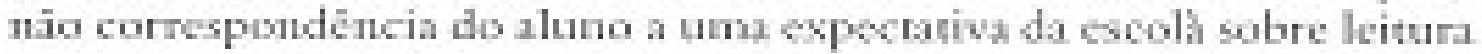

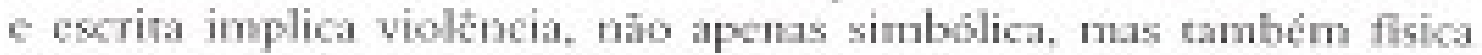
lque batia na gente botava de cusigo quando a gente nio sabia nem

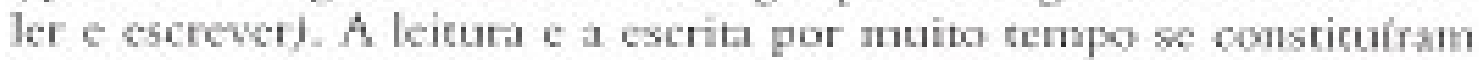

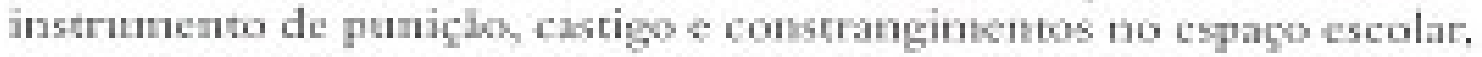
ao mesmo nethe que se val objetivando stas dua priticas como conteúds de cnsino.

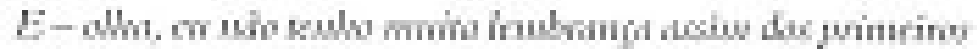

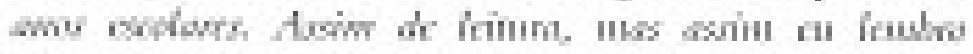

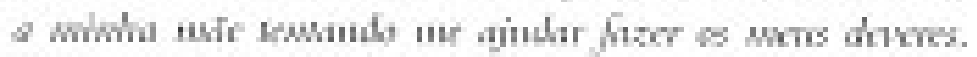

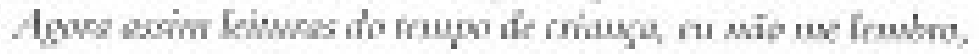

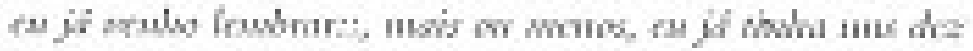

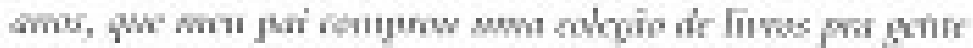

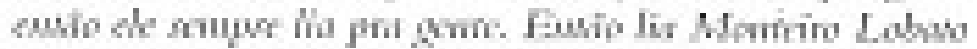

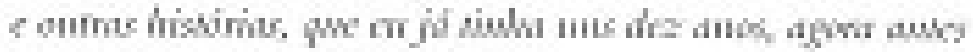
thom withis un novbl [Cl].

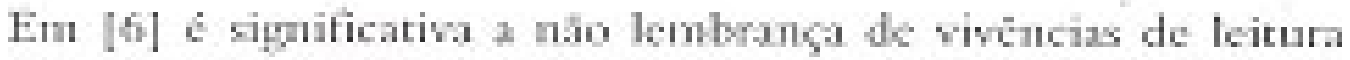

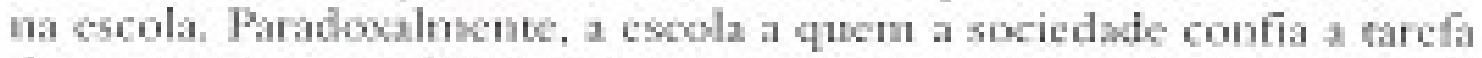
de promower a ampliagho do sceso dos sujeicos a priticis de leitura e

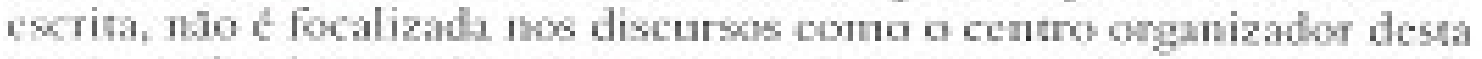
pritica. A lembranca de príicas de keicura ba cscoli se restringe an nero cumprimeno dis bureles prescritas. Na werdade, a figura da mie que

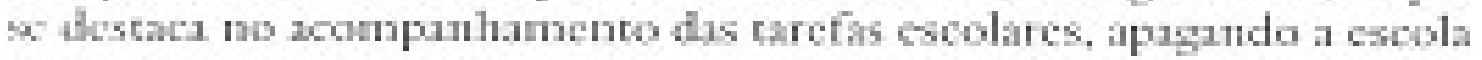

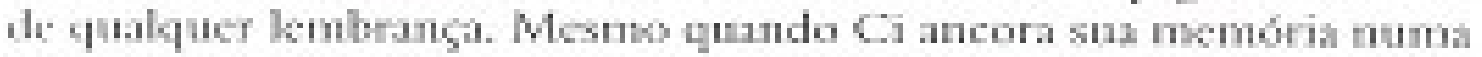

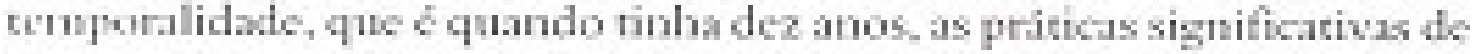

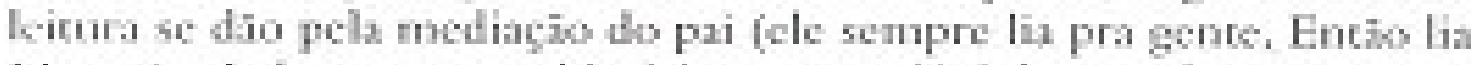

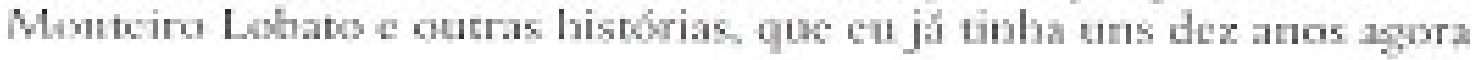




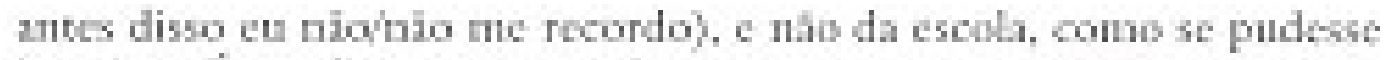

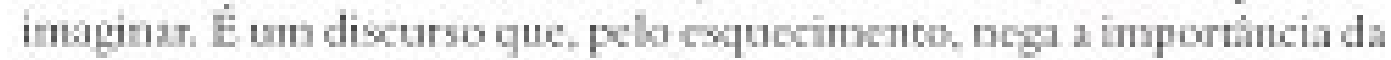

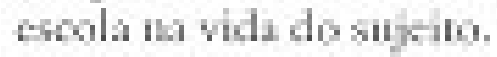

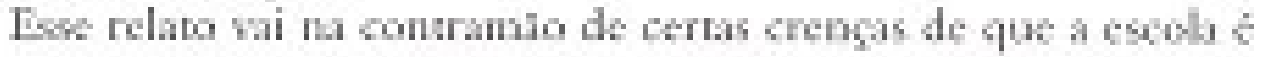

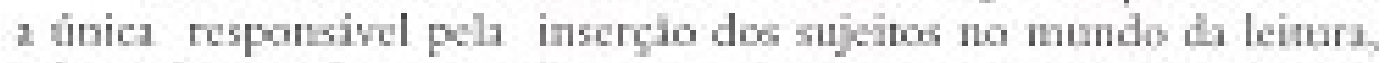
sobretudo quande se trata de sujeitos do ampo, pois pressupse-\$e que

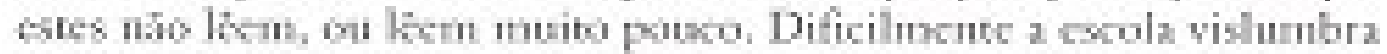

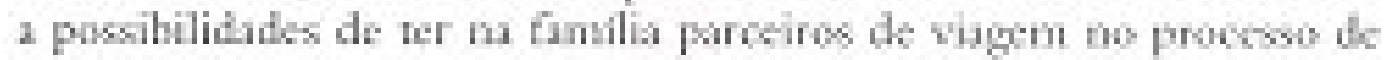

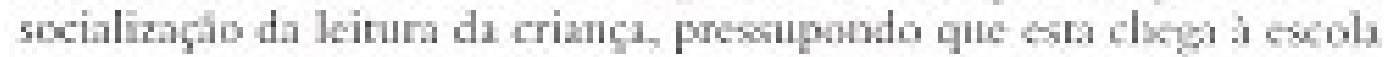

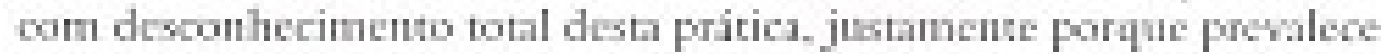

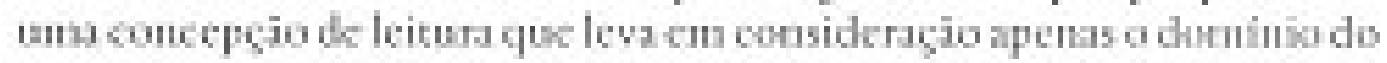

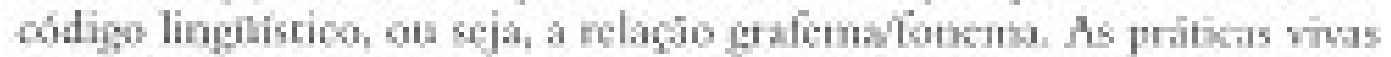

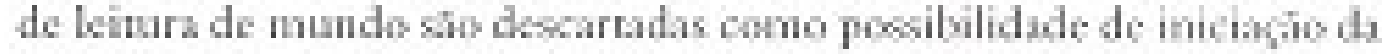
leirora de pulari.

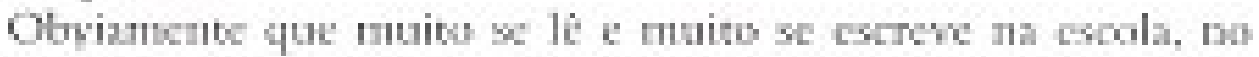

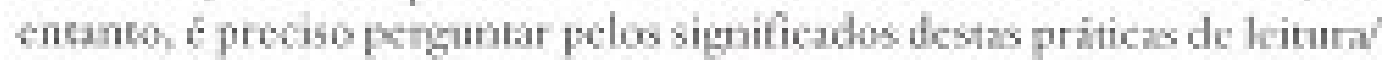

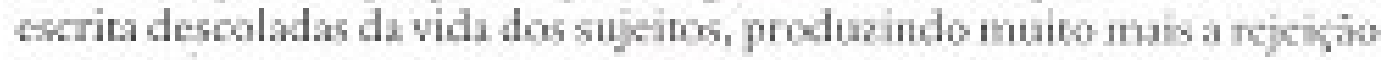
do que proprimente a adesio ll kinara.

33 A vida sogerindo prifices significative de himor

[7]

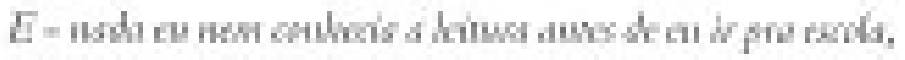

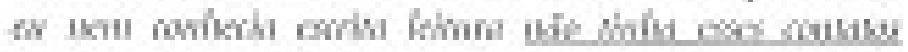

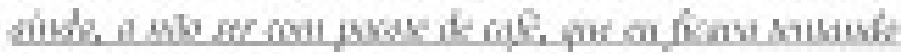

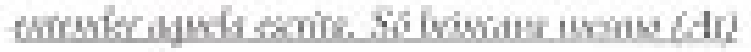

\section{4]}

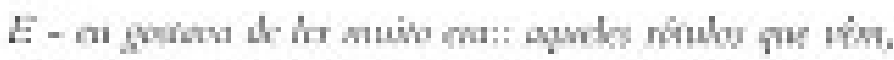

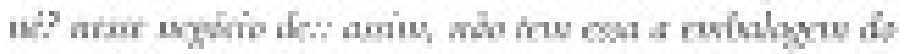

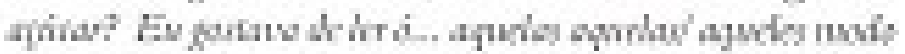

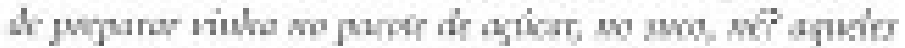

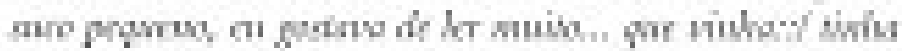

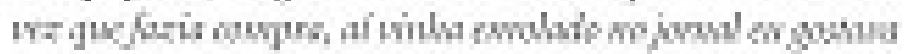

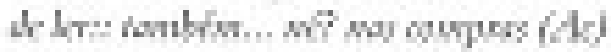

\section{1]}

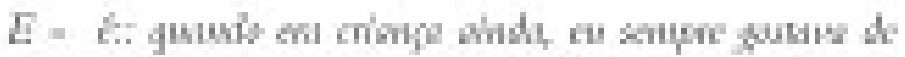

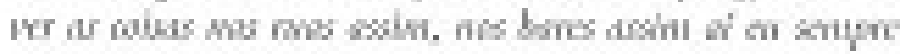




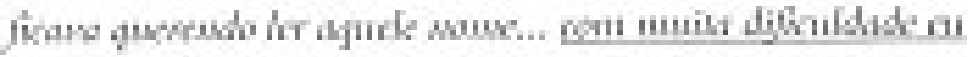

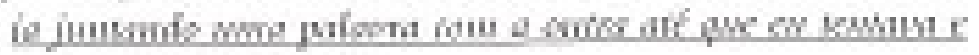
Gond owith thing)

\section{[19]}

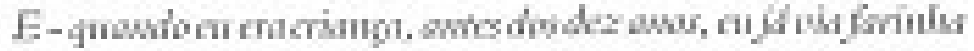

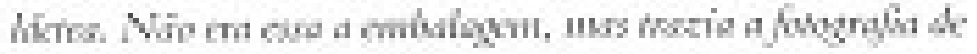

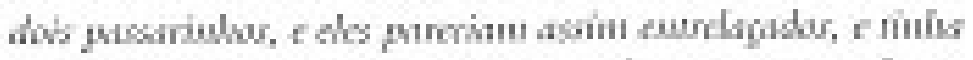

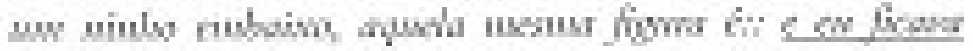

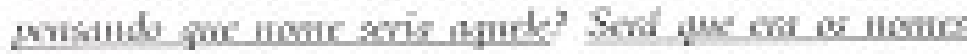

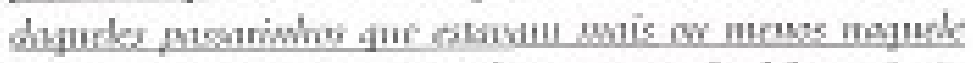

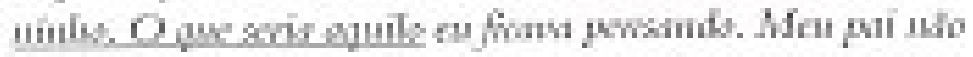

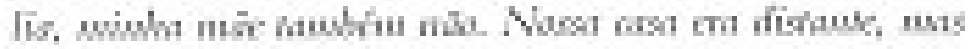

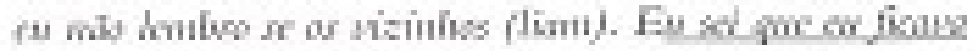

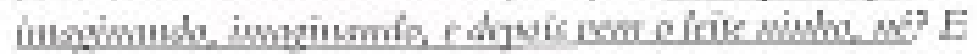

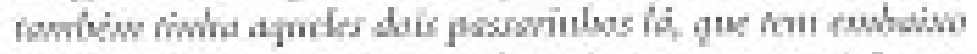

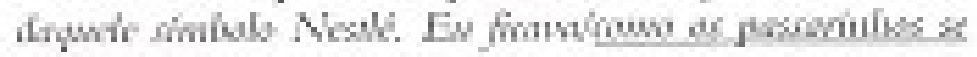

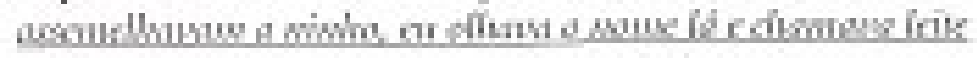

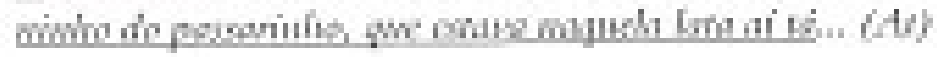

Admitindo com Cenedu [1984] que. mbota submetido a

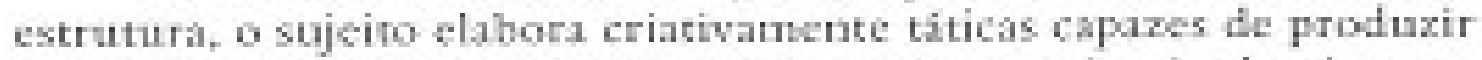
a diferema diquilo que csil prowign pelz maquitaria do siscom: a posingl deprender, dos discursos dos ducandos e eduandas.

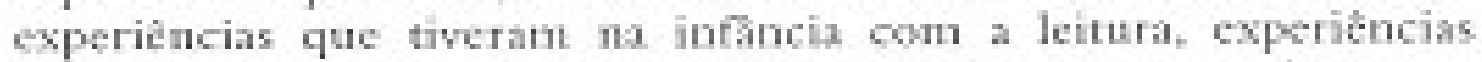
que, se 1 escla so colocuse à escuta da vida dos sujeito, poderian se constituir como ponto de pat lida para as priticas escolares do leinury astitis

Qs recortes $[7]-[8]-[9]$ e [10] nos nosirat indicis do un tribalios inwencivo do sujutes con e na linguagen, construinds

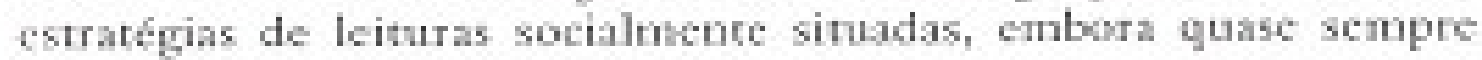

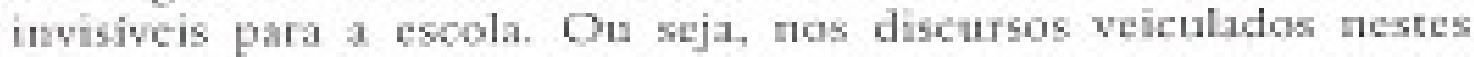
recores temus exemplos de que os sujeirs antes de adouthom os

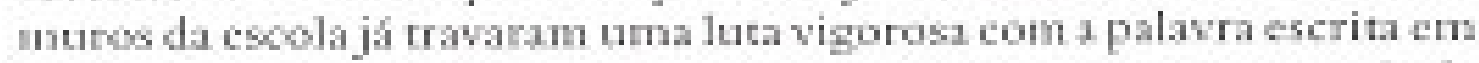

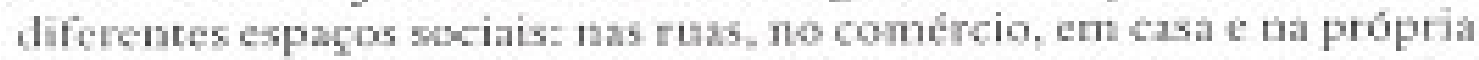

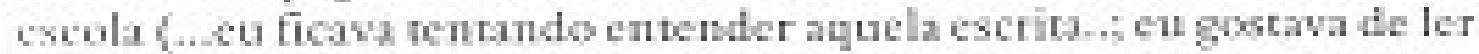

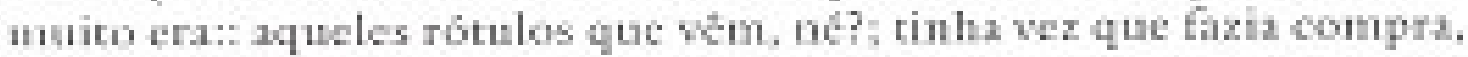

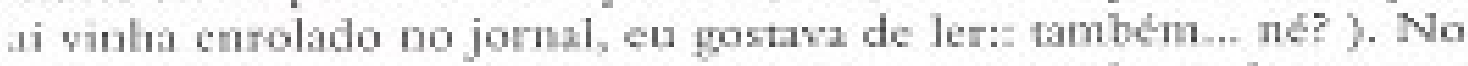

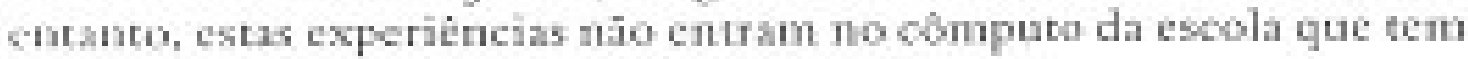




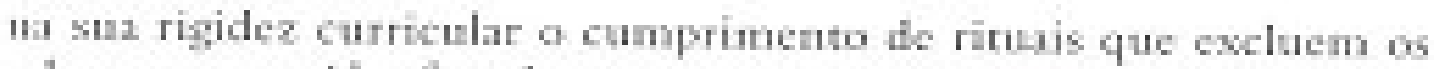
wheres constuitos fard dog seds muros. Foder bohos dizer que nestes discurso temos orienrages metodalogicas exmplues de pono por onds se dewe comegh o trabalho com a leitura a com cocrita

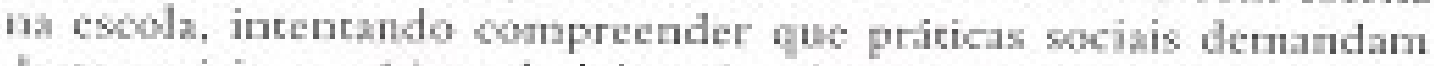

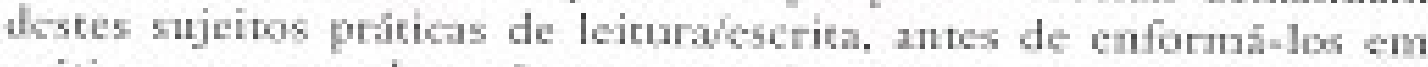
priticas que theidem tho somente interesses ol hegeminicas da cidide das letrac".

\section{CONCLUSAO}

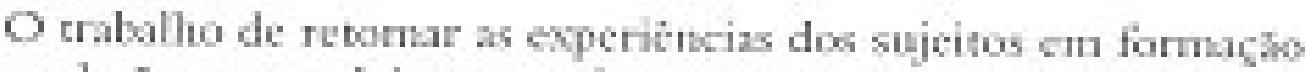

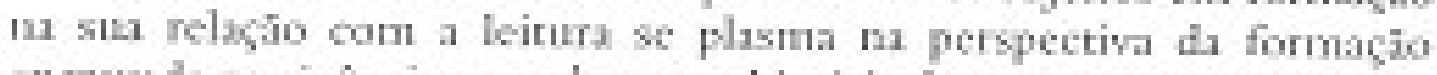

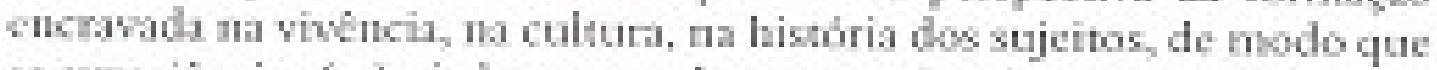

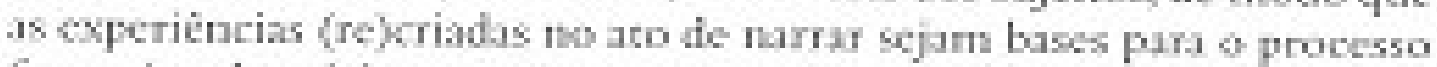

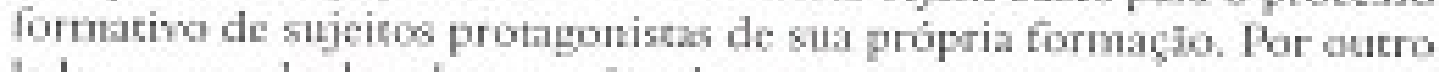

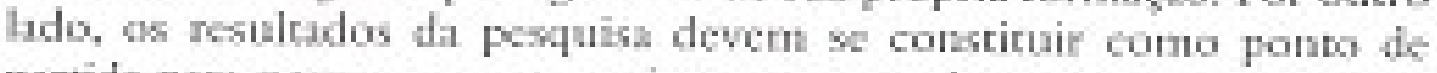

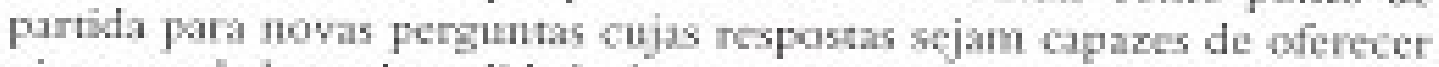

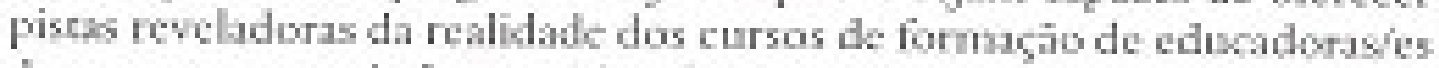

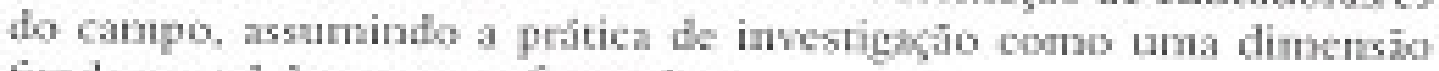
fundament id prowsso tormation.

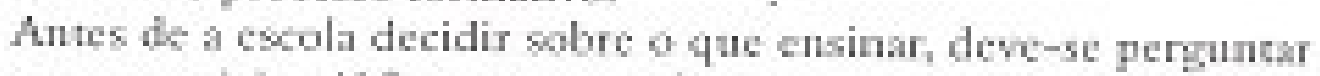

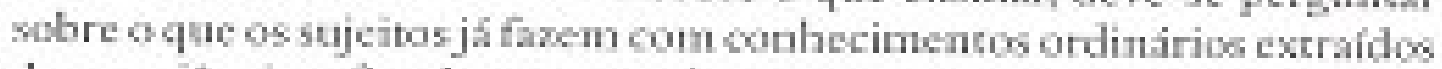

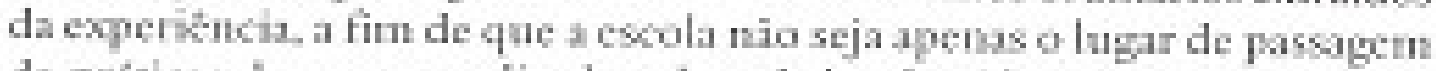

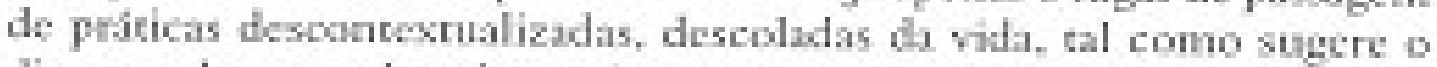

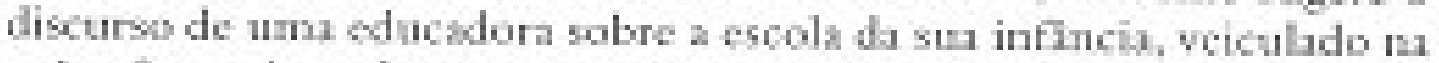

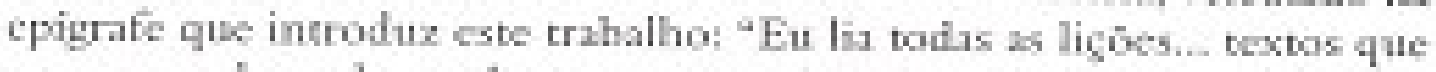

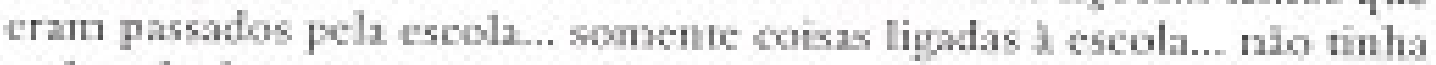
nade whlodo 1 un outro tipo de leitura".

\section{REFERENCLAS}

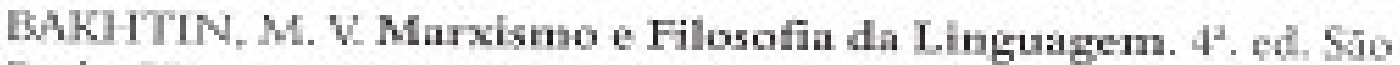
Puto: Huicites, 1988

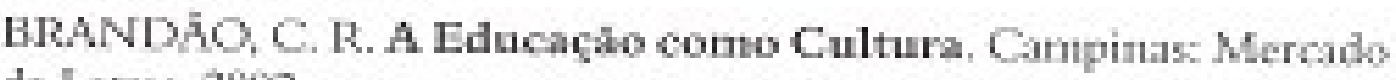
de Leris 20102. 
CERTEAU, M. A Imvençio do Cotidiano: artes de Deer. 6. d. Truducio Ephaimi Ferreira Alws. Tetropols: Woss, 19y.

FREIRE P A Importatua do Ato de Ler. Sio Pulo: Corter, 2001.

GERALDI, J. W Linguagem o Ensino: cuericios de nilitincia. Compinas Mercado de Letras, 1996.

LARROSA, I. Notas sobne a experiencia a a saber da experioncin. WW Geraldi, C. M.G TIOLF1, C. R. GARCLA M de M. (Ors). Fecola

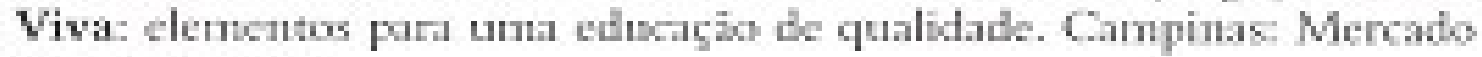
He Letras 2004.

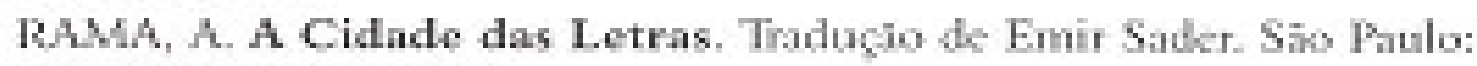
Editora Brasilisase 1094.

TIBELTO, N. Identidade, Memótia e Letramento em Contexto de Fomaço: Educodores of Educadoras do Campo, the prito.

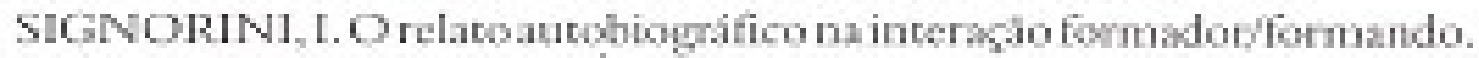
In KLEMLM, A BRMATEICIO M. de L M IOF.j. Letramento e Formaçoño do Professor: priticas disursivas representzocs a constrigio do saber. Gampinas: Mencado de Letras, 2005, pp. 93-125.

Artigo recebido no dia 18 de setembro de 2008 e aprovado no dia 08 de novembro de 2008. 